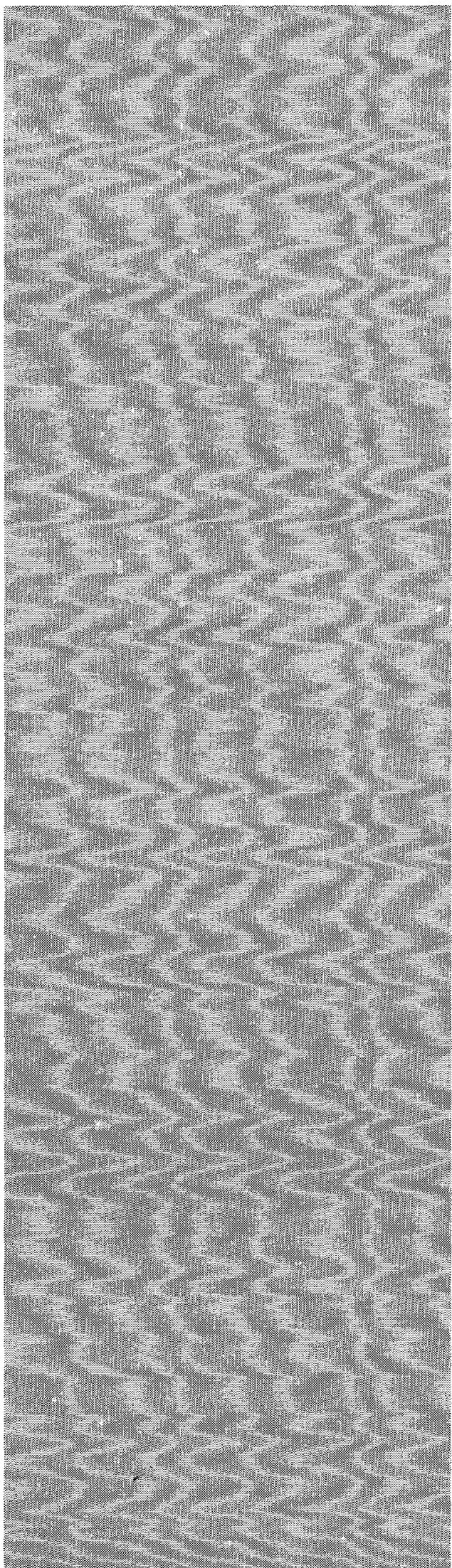

\title{
Uranium Isotopic Analysis with the FRAM Isotopic Analysis Code
}

\section{RECEIVED \\ AUG 121999 \\ OSTI}

\section{Los Alamos \\ NATIONAL LABORATORY}

Los Alamos National Laboratory is operated by the University of California for the United States Department of Energy under contract W-7405-ENG-36. 


\section{Edited by Jeff Skiby, Group CIC-1 \\ Prepared by Rita Romero, Group NIS-5}

This work zoas supported by the US Department of Entergy, Office of Nonproliferation and National Security,

Office of Safeguards and Security.

An Affirmative Action/Equal Opportunity Employer

This report was prepared as an account of work sponsored by an agency of the United States Government. Neither The Regents of the University of California, the United States

Government nor any agency thereof, nor any of their employees, makes any warranty, express or implied, or assumes any legal liability or responsibility for the accuracy, completeness, or usefulness of any information, apparatus, product, or process disclosed, or represents that its use would not infringe privately owned rights. Reference herein to any specific commercial product, process, or service by trade name, trademark, manufacturer, or otherwise, does not necessarily constitute or imply its endorsement, recommendation, or favoring by The Regents of the University of California, the United States Government, or any agency thereof. The views and opinions of authors expressed herein do not necessarily state or reflect those of The Regents of the University of California, the United States Government, or any agency thereof. Los Alamos National Laboratory strongly supports academic freedom and a researcher's right to publish; as an institution, however, the Laboratory does not endorse the viewpoint of a publication or guarantee its technical correctness. 


\section{DISCLAIMER}

Portions of this document may be illegible in electronic image products. Images are produced from the best available original document. 
Uranium Isotopic Analysis with the

FRAM Isotopic Analysis Code

Duc T. Vo

Thomas E. Sampson 

ABSTRACT

I. URANIUM ISOTOPE DECAY CHARACTERISTICS .............................................................. 1

II. CORRECTED BRANCHING RATIOS AND THE COINCIDENCE SUMMING LOSSES OF THE URANIUM GAMMA RAYS ……………......................................................... 2

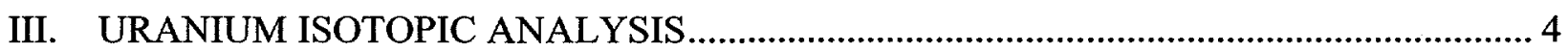

A. Low-Enriched Uranium Isotopic Determination ....................................................... 5

1. FRAM v2.2 with current parameter file ..............................................................5

2. FRAM v2.2 with constrained source-detector distance ......................................8

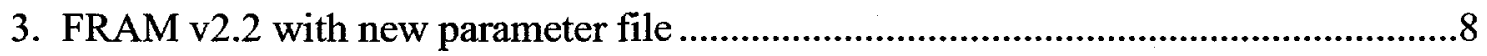

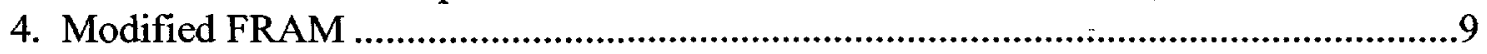

B. High-Enriched Uranium Isotopic Determination ..................................................... 13

1. FRAM v2.2 with current parameter file ................................................................. 12

2. FRAM v2.2 with constrained source-detector distance ......................................... 14

3. FRAM v 2.2 with new parameter file ............................................................... 15

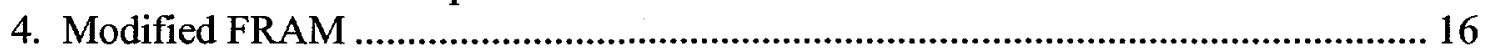

IV. RESULTS WITH THE ARCHIVED DATA ......................................................... 18

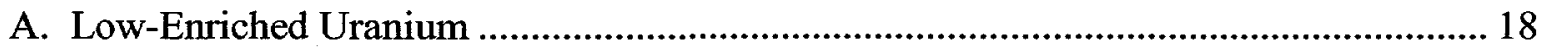

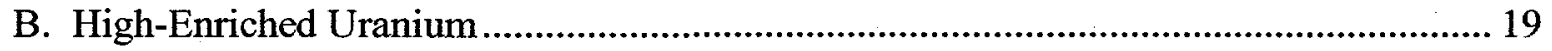

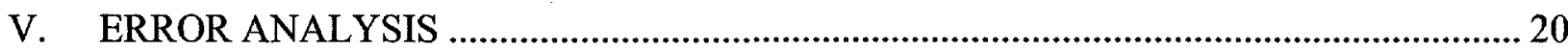

A. Determination Of The True Statistical Error ........................................................ 20

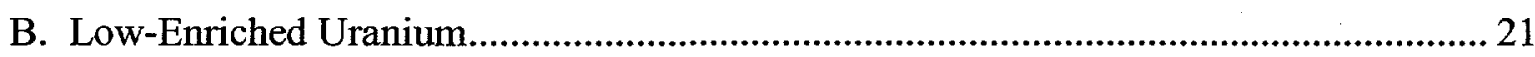

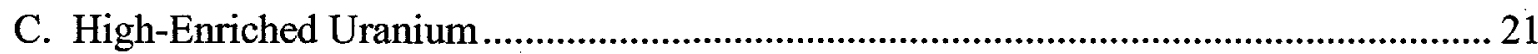

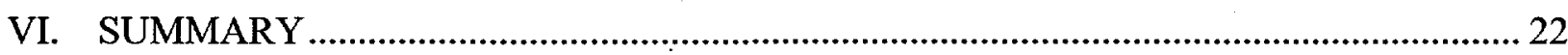

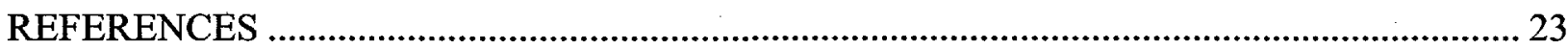




\title{
URANIUM ISOTOPIC ANALYSIS WITH THE FRAM ISOTOPIC ANALYSIS CODE by
}

Duc T. Vo and Thomas E. Sampson

\begin{abstract}
FRAM is the acronym for Fixed-energy Response-function Analysis with Multiple efficiency. This software was developed at Los Alamos National Laboratory originally for plutonium isotopic analysis. Later, it was adapted for uranium isotopic analysis in addition to plutonium. It is a code based on a selfcalibration using several gamma-ray peaks for determining the isotopic ratios. The versatile-parameter database structure governs all facets of the data analysis. User editing of the parameter sets allows great flexibility in handling data with different isotopic distributions, interfering isotopes, and different acquisition parameters such as energy calibration and detector type. ${ }^{1-3}$
\end{abstract}

\section{URANIUM ISOTOPE DECAY CHARACTERISTICS}

Most uranium samples contain the isotopes ${ }^{234} \mathrm{U},{ }^{235} \mathrm{U},{ }^{236} \mathrm{U}$, and ${ }^{238} \mathrm{U}$. Uranium-234 decays by emitting an alpha particle to ${ }^{230} \mathrm{Th}$ with a half-life of $2.446 \mathrm{e} 5$ years. It has only one measurable gamma ray at $120.9 \mathrm{keV}$. Uranium-235 decays by alpha emission to ${ }^{231} \mathrm{Th}$ with a half-life of 7.038e 8 years. It has many intense gamma rays but most of them are below $210 \mathrm{keV}$. Uranium-236 decays to ${ }^{232} \mathrm{Th}$ with a half-life of $3.342 \mathrm{e} 7$ years. It has no measurable gamma rays and its isotopic fraction can not be determined directly from gamma-ray measurements. Uranium-238 decays by alpha-emission to ${ }^{234} \mathrm{Th}$ with a half-life of $4.468 \mathrm{e} 9$ years. Thorium-234, with a half-life of 24 days, in turn decays to ${ }^{234} \mathrm{~Pa}$ by emitting an electron, and the excited ${ }^{234} \mathrm{~Pa}$, with the half-life of 1.2 minutes, decays to ${ }^{234} U$ also by emitting an electron. All the measurable gamma rays of the ${ }^{238} \mathrm{U}$ decay chain came from the decay of ${ }^{234} \mathrm{~Pa}$ to ${ }^{234} \mathrm{U}$. This means that the ${ }^{238} \mathrm{U}$ isotopic fraction can not be accurately determined unless the ${ }^{234} \mathrm{Th}$ has come into secular equilibrium with its ${ }^{238} \mathrm{U}$ parent. After about seven half-lives have elapsed (168 days), the decay rate of ${ }^{234} \mathrm{Th}$ and ${ }^{234} \mathrm{~Pa}$ will become the same as the decay rate of ${ }^{238} \mathrm{U}$. After that time, gamma rays from the decay of ${ }^{234} \mathrm{~Pa}$ can be used as a measure of the amount of ${ }^{238} \mathrm{U}$ in a sample.

In addition to the above uranium isotopes, many high-enriched ${ }^{235} \mathrm{U}$ samples also contain a minute amount of ${ }^{232} \mathrm{U}$ with the half-life of 68.9 years. Neither it nor its direct daughter, ${ }^{228} \mathrm{Th}$ (half-life $=1.91$ years), has any measurable gamma rays. However, some of the daughters in its decay chain, all with the half-lives much less than the half-life of 1.91 years of ${ }^{228} \mathrm{Th}$, have some measurable gamma rays. These gamma rays can be used in the analysis to improve the accuracy of the isotope determination. 


\section{CORRECTED BRANCHING RATIOS AND THE COINCIDENCE SUMMING LOSSES OF THE URANIUM GAMMA RAYS}

It is known that many of the intense gamma rays of ${ }^{238} \mathrm{U}$ decay chain are in coincidence with some other gamma rays. ${ }^{4}$ When one of those gamma rays enters the detector together with one of its coincident gamma rays, the resulting pulse from the detector will not correspond to its energy but to the sum of the two energies or their Compton energies. The result is the loss of counts underneath its peak.

This summing effect is a function of the source-detector distance. As the source is moved farther away from the detector, the solid angle of the detector as seen by the source is reduced and so are the chances for two gamma rays to enter the detector at the same time. Therefore, to accurately determine the isotopic ratios, the branching ratios (BRs) and intensities of these gamma rays need to be corrected for the summing effect before they can be used to determine the relative efficiencies and activities.

To determine the coincidence summing losses of the gamma rays, two sets of data were collected for each of the two sources, $0.71 \%$ and $4.46 \%{ }^{235} \mathrm{U}$ enrichments (the same data sets as in Ref. 4), using a $25 \%$ relative efficiency coaxial detector. One set was with $1.2 \mathrm{~mm}$ of cadmium plus 0.4-mm copper absorbers placed in front of the detector and the other set was without any absorber. The data were obtained with the sources placed at $0,1,3,5,10$, and $15 \mathrm{~cm}$ from the detector's front edge. Twenty-one 1-h spectra were taken at each configuration and they were summed up into one single spectrum to simplify the analysis.

Fixed-energy Response-function Analysis with Multiple efficiency (FRAM) code was used to obtain the areas of the peaks. The peak areas of ${ }^{235} \mathrm{U}$ are then normalized to those of ${ }^{238} \mathrm{U}$ using their known activities. The relative efficiency curve is obtained by fitting some of the normalized peak areas to the equation

$$
\text { Area } / \mathrm{BR}=(\text { Activity }) *(\text { Self atten }) *(\mathrm{Cd}+\mathrm{Cu} \text { atten }) *(\text { Det eff }) *(\text { Correction factor }) .
$$

The correction factor is set equal to $\mathrm{a} E^{\mathrm{b}} \mathrm{c}^{1 / E}$, which was found to work well in correcting for the deviations of the self-attenuation, absorber attenuation, and of the detector efficiency. The energy $E$ is the peak in units of $\mathrm{MeV} ; \mathrm{a}, \mathrm{b}$, and $\mathrm{c}$ are constants. The BRs were taken from Ref. 5 . The 144-, 163-, 186-, and $205-\mathrm{keV}$ peaks of ${ }^{235} \mathrm{U}$ and the $1001-\mathrm{keV}$ peak of ${ }^{238} \mathrm{U}$ were used in the fit.

The variance-covariance matrix from the fit was used to estimate the uncertainties of the relative efficiency curve predicted by the model. The area/BR values of all the peaks were obtained from the relative efficiency curve fit. These were then compared with the measured area/BR values. Figure 1 shows the ratios of the measured area/BR to those from the fit for some of the intense peaks of ${ }^{238} \mathrm{U}$. The 258 - and $946-\mathrm{keV}$ peaks lose a large fraction of their intensity, up to $16 \%$, when the source is moved close to the detector, while for the $766-\mathrm{keV}$ peak, its intensity remains constant regardless of the source-detector distance. Along with the intensitylosses, one can see that the curves resemble the exponential function and are flattening out as the source is moved farther away from the detector. The ratio values of the relative efficiency curves at infinity represent the ratios of the correct BRs to the BRs used in the calculations of the measured area/BR values.

To find the correct BRs and the intensity-losses of the peaks, we fit the nine intense peaks of ${ }^{238} \mathrm{U}$ with large summing losses to the equation $\left[Y=\Sigma a_{i j}-b_{i j} \exp \left(-c X^{d}\right)\right]$, where $i$ represents nine individual energies $(258,569,743,786,880,883,925,927$, and $946 \mathrm{keV})$ of ${ }^{238} \mathrm{U}$ decay chain, $j$ 
represents each of the four data sets, $Y$ is the measured-to-fitted ratio, $X$ is the source-detector distance, and $a, b, c$, and $d$ are some variables. From the fit, the variables $c$ and $d$ are found. The measured-to-fitted ratios of each peak are then fitted to the equation $\left[Y=a-b \exp \left(-c X^{d}\right)\right]$, where $c$ and $d$ are now known constants. The value $a$ found from this fit would correspond to the measured-to-fitted ratio at infinity which is used to calculate the new BR. The value $b / a$ represents the fractional coincidence loss of the peak due to summing at zero distance.
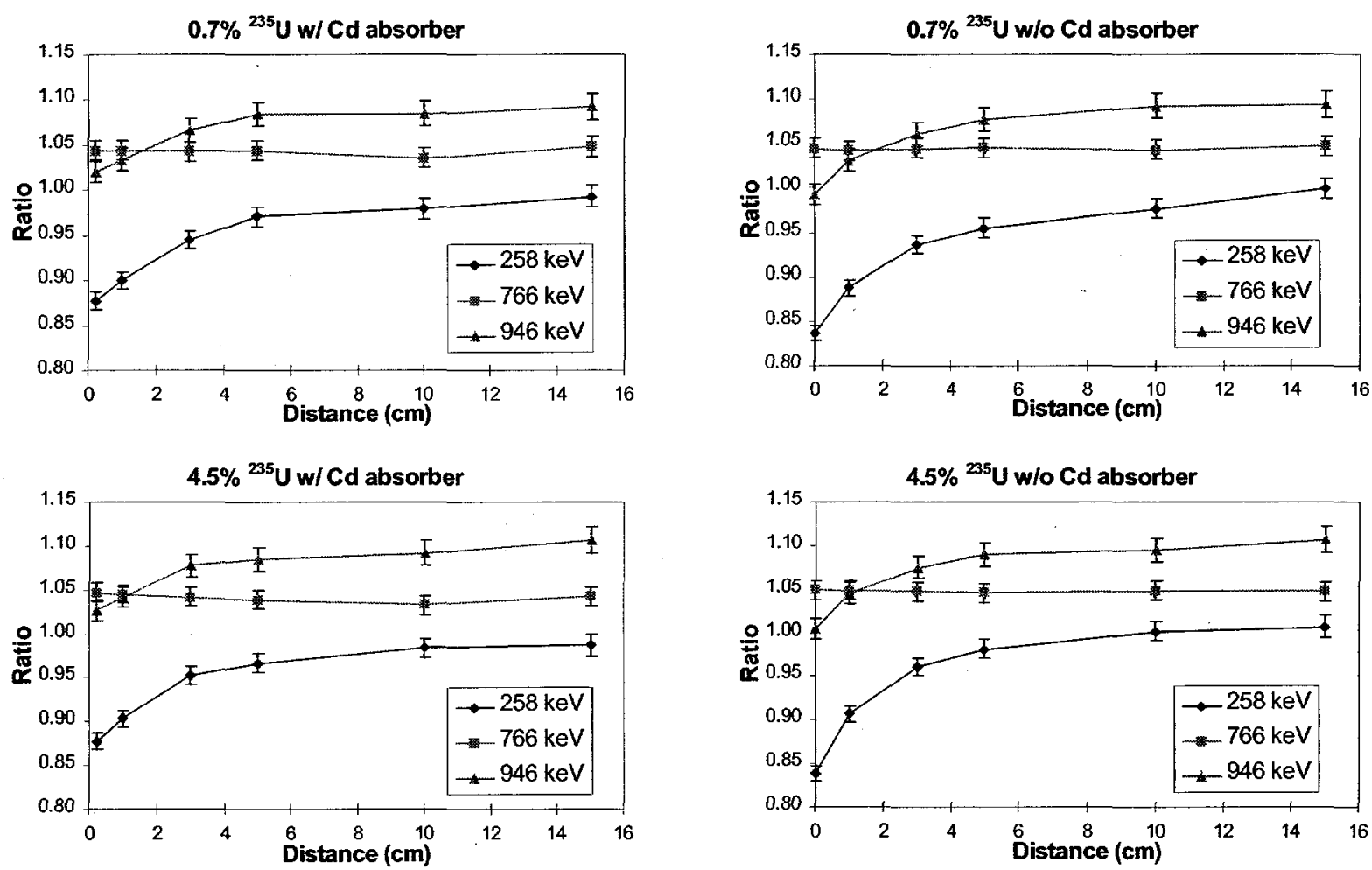

Fig.1. The measured-to-fitted area/BR ratios of some of the peaks of ${ }^{238} U$.

The results of many of the gamma rays of ${ }^{235} \mathrm{U}$ and ${ }^{238} \mathrm{U}$ are presented in Table I. The BR results are the average of all four data sets. The terms "Coinc. Loss" and "Err coinc." in the table represent the relative fractional coincidence-losses due to summing of the gamma rays. For the coincidence summing losses, because in most (if not all) uranium measurements, some cadmium or tin absorber is used to absorb the x-rays, only the average results of the two sets with cadmium absorber are reported.

Additionally, the NBL0005 source $\left(20.06 \%{ }^{235} U\right)$ was also measured. To absorb the lowenergy gamma rays and $\mathrm{x}$-rays, $1.2 \mathrm{~mm}$ of cadmium and $0.4 \mathrm{~mm}$ of copper were used. The data were acquired at 0.2-, 1-, 3-, 5-, 10-, and 15-cm source-detector distances. Eight 1-h cycles were obtained at each setup, and they were summed for the analysis. The analysis was done in a manner similar to that with the $0.71 \%$ and $4.46 \%{ }^{235} \mathrm{U}$ enrichment sources and the results of ${ }^{228} \mathrm{Th}$ decay chain are also reported in Table $I$. The reported BRs of ${ }^{228} \mathrm{Th}$ decay chain are normalized to the decay of ${ }^{228} \mathrm{Th}$. 
Table I. The BRs and fractional coincidence summing losses of the gamma rays obtained in the uranium analysis. The highlighted peaks are the major gamma rays used in the isotopic analysis code FRAM.

\begin{tabular}{|c|c|c|c|c|c|c|c|c|c|c|c|c|c|c|}
\hline energy & BR & BR & $\begin{array}{l}\text { Coinc. } \\
\text { loss }\end{array}$ & $\begin{array}{l}\text { Err } \\
\text { Coinc. }\end{array}$ & & BR & \begin{tabular}{|l|l|} 
Err BR \\
\end{tabular} & nc. & $\begin{array}{l}\text { Err } \\
\text { Coint }\end{array}$ & ergy & BR & BR & $\begin{array}{l}\text { oinc. } \\
\text { ss }\end{array}$ & $r$ \\
\hline \multicolumn{5}{|c|}{ Uranium-235 } & \multicolumn{5}{|c|}{ Uranium-238 } & \multicolumn{5}{|c|}{ Uranium-238 } \\
\hline & $620 \mathrm{E}-3$ & $8.2 E-5$ & & & & $550 \mathrm{E}-5$ & $4.5 \mathrm{E}-7$ & & & & $2.752 \mathrm{E}-5$ & $6.3 \mathrm{E}-7$ & & \\
\hline & $35 \mathrm{E}-1$ & E-4 & 100 & & & & & & & & $18 E-6$ & & & \\
\hline .93 & $23 E-4$ & $3 E-5$ & 0.163 & 0.082 & 3.80 & $30 E-6$ & $E-8$ & 128 & 066 & 9.20 & $3.344 \mathrm{E}-5$ & $2 E-7$ & 53 & \\
\hline & $89 E-2$ & & 002 & 0.006 & & $E-5$ & & & 066 & & & & & \\
\hline 2.61 & D24E-3 & $\mathrm{OE}-4$ & 0.081 & 0.036 & 5.20 & $967 E-5$ & $4 \mathrm{E}-7$ & 371 & 0.082 & 25.10 & $2.978 E-5$ & $4 \mathrm{E}-7$ & 126 & .05 \\
\hline & $39 \mathrm{E}-1$ & $2 E-3$ & 0.000 & 0.006 & 3.80 & 814E-5 & $2 \mathrm{E}-7$ & & 0.021 & 25.60 & $1.933 E-5$ & $9 \mathrm{E}-7$ & 060 & 0 \\
\hline & $3 E-3$ & $5 E-5$ & 001 & 10 & & & E-6 & & 021 & 9.30 & $7.809 E-6$ & & 00 & 0 \\
\hline .90 & $536 E-4$ & $6 E-6$ & 0.035 & 0.045 & 16.50 & $268 E-6$ & 1E-7 & 257 & 195 & 1.45 & $652 E-5$ & $2 \mathrm{E}-7$ & 045 & 01 \\
\hline & $E-2$ & $9 E-5$ & 0.042 & & & & & & & & $6 E-5$ & $E-7$ & 089 & .02 \\
\hline 31 & $993 E-2$ & $3 E-4$ & 0.000 & 008 & & $079 E-6$ & $E-7$ & 318 & 0.238 & 66.60 & $8.808 E-6$ & & 233 & .13 \\
\hline & $7 E-4$ & 7E-6 & 0.000 & 0.054 & 4.50 & $1.786 E-5$ & $3 E-7$ & 165 & 0.063 & 76.00 & 4.472E-5 & $5.6 \mathrm{E}-7$ & .011 & .02 \\
\hline & $E-3$ & $E-5$ & 015 & 024 & & $E-6$ & $E-7$ & 06 & 602 & 30.45 & $\mathrm{E} 4$ & $=-6$ & 074 & .01 \\
\hline .50 & $3 E-4$ & $1 E-6$ & 0.061 & 0.054 & 3.90 & 7.967E-6 & $O E-6$ & .076 & 0.198 & 83.22 & $1 E-4$ & $5 E-6$ & 088 & .01 \\
\hline & $4 \mathrm{E}-4$ & $7 \mathrm{E}-6$ & 013 & 029 & & $1.926 \mathrm{E}-5$ & $4 \mathrm{E}-7$ & & 063 & 7.28 & E-5 & $5 E-7$ & 08 & .02 \\
\hline 84 & $E-4$ & $9 E-6$ & 0.039 & 037 & .70 & $1.665 E-5$ & $8 E-7$ & 035 & 0.065 & 98.67 & $\mathrm{E}-5$ & & 031 & .01 \\
\hline & $E-4$ & $8.8 E-6$ & 0.000 & 0.134 & .90 & $7.355 E-6$ & $5 E-7$ & 67 & 142 & 4.20 & $94 \mathrm{E}-6$ & $8 \mathrm{E}-7$ & 136 & .10 \\
\hline & $E-4$ & $5 E-6$ & 00 & 337 & & & & & 24 & & & & & .02 \\
\hline .50 & $1.274 E-4$ & 2.0E-5 & 0.050 & 1.088 & 2.60 & 983E-5 & $7.8 \mathrm{E}-7$ & 117 & 0.113 & 90 & $4 E-4$ & & 084 & .01 \\
\hline & $204 E-4$ & & 0.000 & 0.209 & 5.50 & $5.915 \mathrm{E}-6$ & 1.3E-6 & & 0.608 & 25.80 & $3.760 \mathrm{E}-5$ & & .075 & 0.01 \\
\hline \multicolumn{5}{|c|}{ Uranium-238 } & 99.03 & $6.031 E-5$ & 1.1E-6 & 0.054 & 0.036 & 926.60 & $1.651 \mathrm{E}-5$ & $9.1 E-8$ & .075 & 0.01 \\
\hline & $785 E-4$ & $5.6 \mathrm{E}-6$ & 0.005 & & & & & & & & & & & 01 \\
\hline & $E-5$ & $9 \mathrm{E}-6$ & 0.378 & 0.136 & & $E-5$ & $2 \mathrm{E}-7$ & 0.091 & 0.038 & 5.80 & $E-7$ & $E-8$ & 175 & .17 \\
\hline & $\mathrm{E}-5$ & 1.7E-6 & 0.180 & 0.053 & (0) & 7.66 & $5.4 \mathrm{E}-7$ & & 0.1 & & $6 \mathrm{E}-5$ & & & 0.17 \\
\hline & 9.619 & $2.5 E-6$ & 0.208 & 0.084 & & $9.623 E-6$ & $5.2 \mathrm{E}-7$ & & & & E-5 & & .082 & 0.03 \\
\hline 22 & $E-5$ & $1.3 E-6$ & 14 & & & & & & & 96 & & $=-6$ & & . \\
\hline & & & & & & & & & & & & & & 1.04 \\
\hline & & $7 \mathrm{E}-7$ & & & & & & & & & & & & .07 \\
\hline & $.061 E-5$ & 1.3E-6 & 0.069 & & & & $1.3 \mathrm{E}-6$ & & & & & & & \\
\hline & $4.575 \mathrm{E}-5$ & 2.2E-6 & 0.053 & 0.073 & & $E-4$ & $4.3 E-6$ & & & & & & .035 & 0.08 \\
\hline 90 & 2.426E-5 & $1.7 \mathrm{E}-6$ & 0.125 & 0.065 & & & $6 \mathrm{E}-7$ & & 0.0 & & BE-5 & & & 0.05 \\
\hline & $2.730 \mathrm{E}-5$ & $7.1 \mathrm{E}-7$ & 0.066 & 0.073 & & 3.07 & & & 0.0 & & $5.656 \mathrm{E}-5$ & & & 0.05 \\
\hline & $1.585 \mathrm{E}-5$ & $6.6 \mathrm{E}-7$ & 0.022 & 0.104 & & & $5.2 E-7$ & & 0.0 & & 8.371E-3 & $3.5 \mathrm{E}-5$ & 000 & 0.01 \\
\hline & $1.858 E-5$ & $5.2 \mathrm{E}-7$ & 0.114 & 0.072 & & $7.576 \mathrm{E}-5$ & $7.8 E-7$ & 0.048 & 0.022 & \multicolumn{5}{|c|}{ Thorium-228 } \\
\hline 3.40 & 2.241E-5 & $6.5 \mathrm{E}-7$ & 0.092 & 0.083 & 786 & & $7 E-6$ & & 0.0 & & $494 \mathrm{E}-1$ & & 000 & .00 \\
\hline & $6.392 \mathrm{E}-6$ & 6.2E-7 & & & & & & & & & & & & .02 \\
\hline 475.75 & $2.393 E-5$ & $6.5 \mathrm{E}-7$ & 0.080 & 0.055 & & $4.992 E-5$ & $5.5 E-7$ & & 0.023 & & & $=-3$ & 037 & 0.02 \\
\hline 481.00 & $6.766 \mathrm{E}-6$ & $5.9 \mathrm{E}-7$ & 0.209 & 0.163 & 805.74 & $9.509 E-5$ & 1.1E-6 & 0.145 & 0.026 & 860.50 & $4.596 \mathrm{E}-2$ & $1.2 \mathrm{E}-3$ & 0.103 & 0.03 \\
\hline
\end{tabular}

\section{URANIUM ISOTOPIC ANALYSIS}

FRAM employs a single coaxial germanium detector to acquire uranium data. It uses the gamma rays in the range of $120 \mathrm{keV}$ up to $1001 \mathrm{keV}$. The code fits the areas of the gamma-ray peaks using the response function method, which requires only linear least-square fitting. To determine the relative efficiency curve, the code fits a polynomial function in the logarithm of the energies to the relative efficiency data. It has the form

$$
\ln (\mathrm{Area} / \mathrm{BR})=C_{1}+C_{2} / E^{2}+C_{3} \ln E+C_{4}(\ln E)^{2}+C_{5}(\ln E)^{3}+C_{i}
$$


where $E$ is the energy in $\mathrm{MeV}$. Each $C_{i}$ is associated with isotopes beyond the first one; $i$ ranges in value from 6 to $5+(\mathrm{N}-1) ; \mathrm{N}$ is the number of isotopes.

One of the main features of FRAM is its user-editable parameter database, which governs the analysis. A complete group of parameters in the database is called a parameter set or parameter file. Parameter files are easily modified to accommodate different data analysis.

The low-enriched uranium analysis employs many gamma rays of ${ }^{235} \mathrm{U}$ and ${ }^{238} \mathrm{U}$. One of the main gamma rays that govern the isotopic ratios of uranium is the $258-\mathrm{keV}$ peak of ${ }^{238} \mathrm{U}$. Figure 2 shows the 258-keV peak and some other gamma rays for different enrichment uranium. The $258 \mathrm{keV}$ peak appears strongly in natural uranium. As the enrichment increases, the 258-keV peak appears less intense and the peaks of ${ }^{235} \mathrm{U}$ and ${ }^{228} \mathrm{Th}$ start to grow. At very high enrichment, the $258-\mathrm{keV}$ peak is about to completely disappear.

The 258-keV gamma ray is the most important peak in determining the fraction of ${ }^{238} \mathrm{U}$ in low-enriched uranium. As seen in Fig. 2, when the enrichment is high, its intensity becomes very weak and unusable. Therefore, a different analysis, which does not strongly depend on the $258-\mathrm{keV}$ peak, is needed for high-enriched uranium. Because in almost all high-enriched uranium there exists some trace of ${ }^{228} \mathrm{Th}$ (as seen in Fig. 2), some of the gamma rays in ${ }^{228} \mathrm{Th}$ can be used to determine the isotopic ratios.

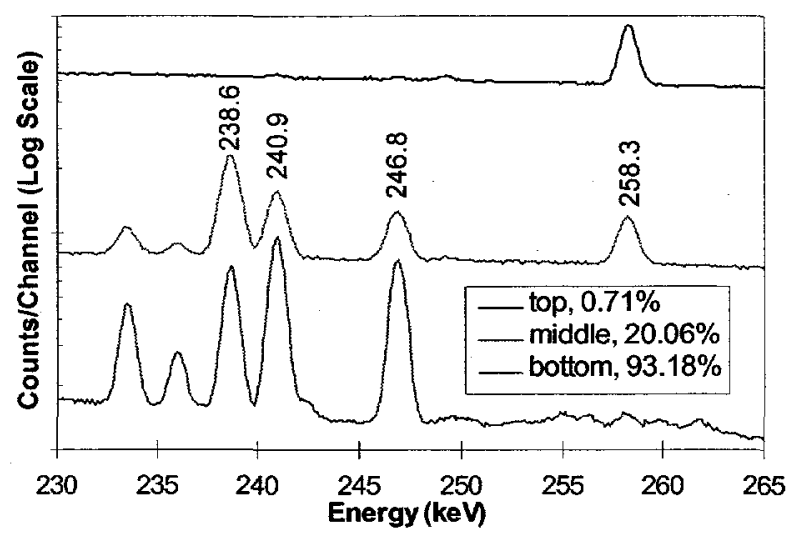

Fig. 2. Peak intensity as a function of uranium enrichment. The $238.6-\mathrm{keV}$ peak is from ${ }^{228} \mathrm{Th}$, the 240.9- and 246.8-keV peaks are from ${ }^{235} \mathrm{U}$, and the 258.3-keV peak is from ${ }^{238} \mathrm{U}$. Spectra are shifted vertically for clarity.

For uranium isotopic analysis, FRAM uses two different parameter files to analyze the isotopic ratios: one for low-enriched ${ }^{235} \mathrm{U}$ (up to $70 \%$ enrichment) and the other for high-enriched ${ }^{235} \mathrm{U}$ (greater than $10 \%$ enrichment). There is the overlap between the two regions, for ${ }^{235} \mathrm{U}$ enrichment between $10 \%$ to $70 \%$, one can use either the low- or high-enriched parameter file for analysis.

In this section, the analysis is divided into two parts, low-enriched uranium and highenriched uranium. For each part, four different methods of analyzing uranium data are presented. These methods are being studied for incorporation in future versions of FRAM.

\section{A. Low-Enriched Uranium Isotopic Determination}

1. FRAM v2.2 with current parameter file. The current low-enriched parameter file uses the gamma rays of ${ }^{235} \mathrm{U}$ and ${ }^{238} \mathrm{U}$ to determine the relative efficiency curve. the BRs for ${ }^{235} \mathrm{U}$ are taken from Ref. 6 . the BRs for ${ }^{238} \mathrm{u}$ are from Ref. 7, except the br of the 258-kev gamma ray, which was adjusted to match the data better.

For uranium determination, the current parameter file uses the 144-, 163-, 186-, 195-, and 
205-keV peaks of ${ }^{235} \mathrm{U}$ and the 258-, 743-, 766-, 880-, 883-, 946-, and 1001-keV peaks of ${ }^{238} \mathrm{U}$ and its daughters to determine the relative efficiencies. From the peaks used, we see that there is no overlap of peaks between the gamma rays of ${ }^{235} \mathrm{U}$ and ${ }^{238} \mathrm{U}$. Also, a large gap exists between the $258-$ and $743-\mathrm{keV}$ peak of ${ }^{238} \mathrm{U}$. This in effect makes the $258 \mathrm{-keV}$ peak the driving force of fitting the relative efficiency curve, and therefore, it is the only peak used for the activity of ${ }^{238} \mathrm{U}$. Figure 3 shows an example of a relative efficiency curve using the current low-enriched uranium parameter file.

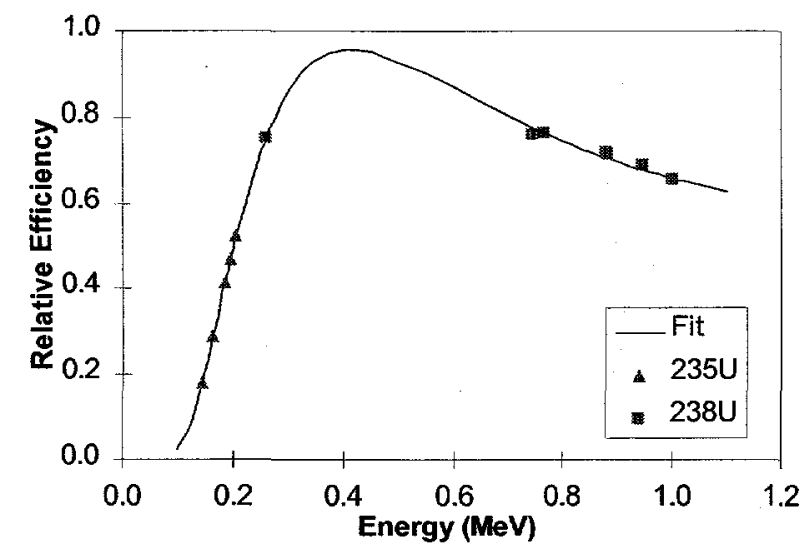

Fig. 3. Example of a relative efficiency curve of lowenriched uranium $\left(4.46 \%{ }^{235} U\right)$.

Because the $258-\mathrm{keV}$ peak is the only peak used to determine the activity of ${ }^{238} \mathrm{U}$, we see that the ${ }^{235} \mathrm{U} /{ }^{238} \mathrm{U}$ ratio depends mostly on the determination of the $258 \mathrm{-keV}$ peak. If the BR of the $258-\mathrm{keV}$ peak is not correct, or if some of its area underneath its peak in the spectrum is lost due to summing, then the ${ }^{235} \mathrm{U} /{ }^{238} \mathrm{U}$ ratio will likely not be correct.

From Table I, we see that the fractional coincidence summing loss of the $258 \mathrm{-keV}$ peak of ${ }^{238} \mathrm{U}$ is large. Therefore, it is very likely to be affected by the summing effect, which depends on the solid angle of the detector that the source sees. For a certain detector, the solid angle of the detector in turn is a function of the source-detector distance. Figure 4 shows the results of the analysis with FRAM v2.2 using the current parameter file for low-enriched uranium. The data acquisition time for the NBS071 and NBS446 with 1.2-mm cadmium data was $21 \mathrm{~h}$ each. For the NBS446 data with the steel absorber of $1.7 \mathrm{~cm}$ thick, the acquisition time was $15 \mathrm{~h}$ each except for the one at the 1.7-cm distance, which was acquired in $5 \mathrm{~h}$. The NBL2006 acquisition time was $8 \mathrm{~h}$ each. The notation for these sources is that the last three or four digits represent the fraction of the ${ }^{235} \mathrm{U}$ enrichment. The error bars represent the true statistical errors of the data and are discussed later in the text.

We clearly see from Fig. 4 that the ${ }^{235} \mathrm{U} /{ }^{238} \mathrm{U}$ bias is a function of source-detector distance. The bias varies from $4 \%$ for the source in contact with the cadmium absorber and the detector ( $2 \mathrm{~mm}$ from the detector) to $-12 \%$ for the source at about $15 \mathrm{~cm}$ from the detector. Clearly, for the FRAM code to work well with low-enriched uranium, one needs to remove the source-detector dependency by some means. 


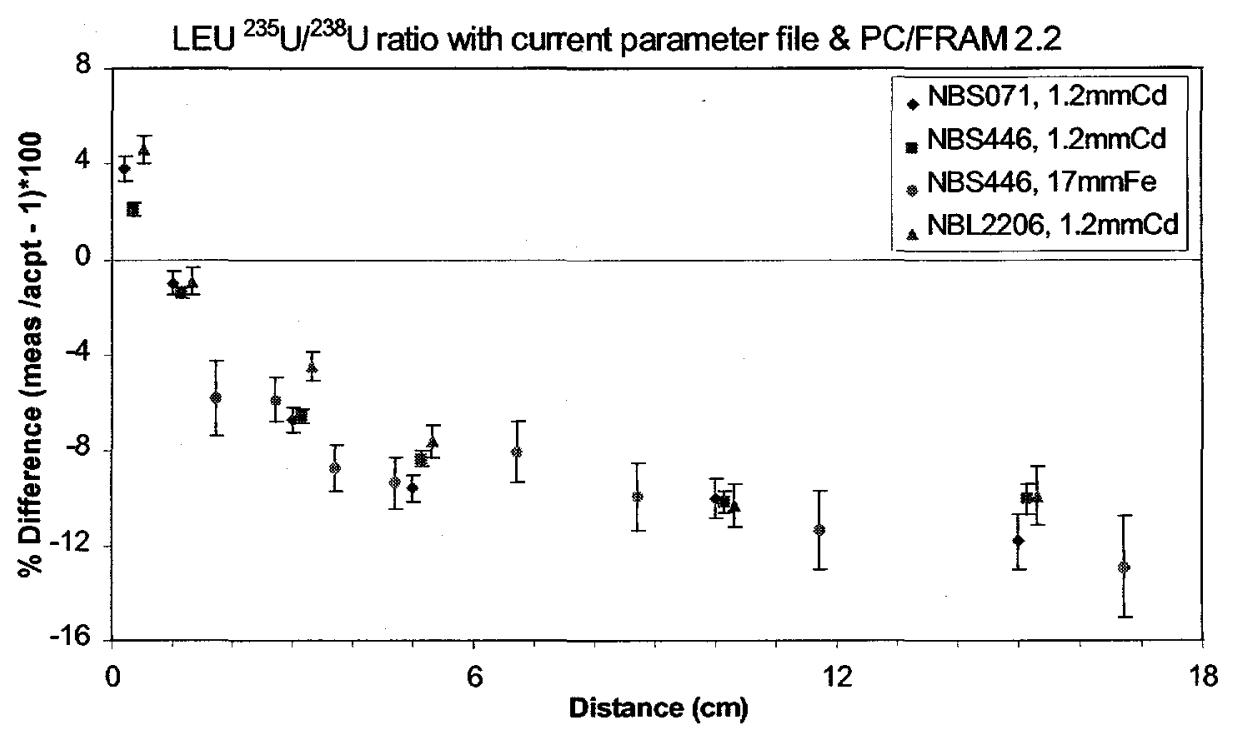

Fig. 4. Measurement bias as a function of source-detector distance. The horizontal values of NBS446 and NBL2206 are shifted slightly to the right for clarity. The NBS071 and NBS446 have the ${ }^{235} U$ enrichments of $0.71 \%$ and $4.46 \%$, respectively. The $N B L 2006$ is $20.06 \%{ }^{235} U$ enriched. The values after the source names in the legend represent the type and thickness of the absorbers.

2. FRAM v2.2 with constrained source-detector distance. One simple method of reducing the source-detector distance dependency is to constrain the source-detector distance to greater than $5 \mathrm{~cm}$. The BR of the $258-\mathrm{keV}$ peak of ${ }^{238} \mathrm{U}$ is then adjusted accordingly to shift the ${ }^{235} \mathrm{U} /{ }^{238} \mathrm{U}$ ratios upward to agree with the accepted results. If the $258 \mathrm{-keV}$ peak BR is adjusted upward by $10 \%$ (from $6.904 \mathrm{e}-4$, which is already an adjusted value, to $7.594 \mathrm{e}-4$ ), then the bias would now vary only from about $2 \%$ for the source detector of $5 \mathrm{~cm}$ to about $-2 \%$ for the source detector of $15 \mathrm{~cm}$. Figure 5 shows the results. 


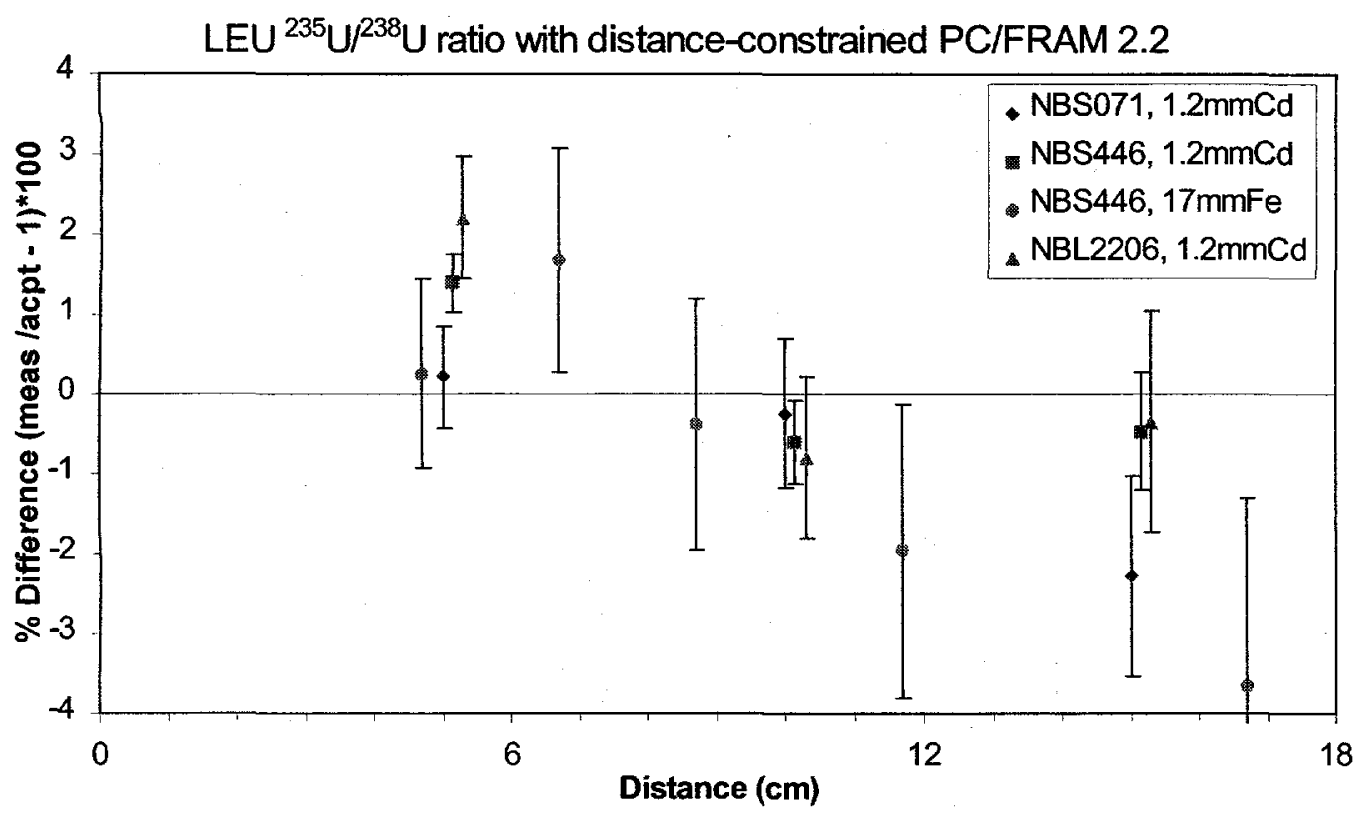

Fig. 5. Measurement bias as a function of source-detector distance.

Note that this $5-\mathrm{cm}$ constraint is for the thick sources used $(2.1 \mathrm{~cm}$ thick). To achieve this small source-detector distance bias with thin sources, the constraint may be greater than a $6-\mathrm{cm}$ distance.

The big setback of this method is clearly the constrained source-detector distance. For a very weak uranium source, it may not be possible to effectively measure the isotopic ratios if the source has to be far from the detector.

3. FRAM v2.2 with new parameter file. Another method, which can remove most of the source-detector distance dependency without the distance constraint, may prove more efficient than the above method. This method can use the current FRAM v2.2 code without any modification.

Figures 6 and 7 show the relative efficiency curves of low-enriched uranium. The crosses are the real data of ${ }^{238} \mathrm{U}$ where some peaks experience some coincidence summing losses. The squares represent the data of ${ }^{238} \mathrm{U}$ without any coincidence summing losses. These data points were calculated from the actual data points by adding the counts corresponding to the coincidence summing losses to the peak areas. 


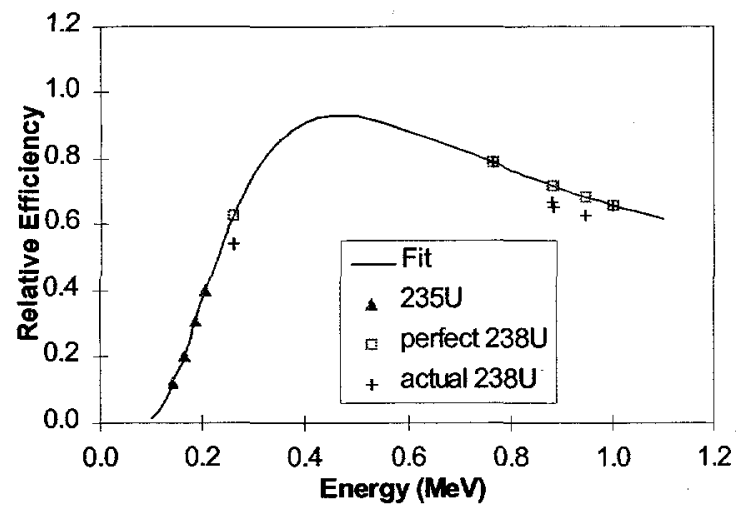

Fig. 6. Example of a relative efficiency curve of lowenriched uranium $\left(4.46 \%{ }^{235} \mathrm{U}\right)$. The curve is fitted using the perfect ${ }^{238} U$ data points.

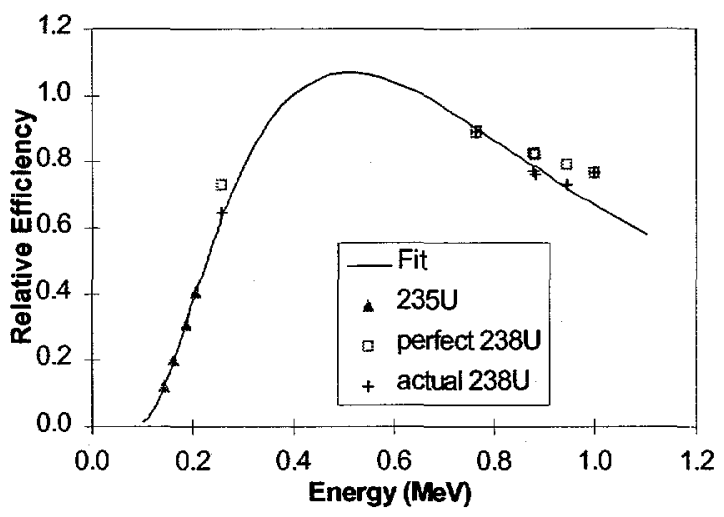

Fig. 7. The ${ }^{238} U$ data points are re-normalized and fitted. The curve is fitted using the actual ${ }^{238} U$ data points (except the 1001-keV peak).

To fit the data through the ${ }^{235} \mathrm{U}$ and the ${ }^{238} \mathrm{U}$ data points, the two sets of data $\left({ }^{235} \mathrm{U}\right.$ and ${ }^{238} \mathrm{U}$ ) are fitted and normalized to match one another. If there were no coincidence summing losses, then the curve would look like that in Fig. 6. The actual data show the deviations from the perfect intensities of the 258-, 880-, 883-, and 946-keV peaks.

Figure 7 shows the fit through the actual data points. The $1001-\mathrm{keV}$ peak is not used in this fit. In this figure, the ${ }^{238} \mathrm{U}$ data points appear to be higher than those in Fig. 6 . It is because of the intensity losses from coincidence summing of the peaks, especially that of the $258-\mathrm{keV}$ peak of ${ }^{238} \mathrm{U}$, that the ${ }^{235} \mathrm{U}$ and ${ }^{238} \mathrm{U}$ data sets are normalized differently than in Fig. 6. The ${ }^{238} \mathrm{U}$ normalization fraction from this second normalization is smaller than that in the normalization of the perfect data by about the same amount as the intensity loss of the $258 \mathrm{-keV}$ peak. If any ${ }^{238} \mathrm{U}$ data points on or near this relative efficiency curve are used to calculate the activity of ${ }^{238} \mathrm{U}$, then the ${ }^{238} \mathrm{U}$ isotopic fractional result will be too low. Note that, from Fig. 7 , the actual $1001-\mathrm{keV}$ peak intensity is higher than the efficiency curve by about the same fraction as the perfect $258-\mathrm{keV}$ peak intensity, which is also about the same as the fractional loss of the ${ }^{238} \mathrm{U}$ normalization fraction. So if the $1001-\mathrm{keV}$ peak is the only peak used to obtain the ${ }^{238} \mathrm{U}$ activity, then the result should be about right.

Figure 8 shows the results of the analysis with FRAM v2.2 using the new parameter file for low-enriched uranium. This parameter file uses the 258-, 766-, 880-, 883-, and 946-keV peaks for the relative efficiency and only the $1001-\mathrm{keV}$ peak for the activity of ${ }^{238} \mathrm{U}$. The BRs are from Table 1. The results appear much better than those from FRAM v2.2 with the current parameter file and somewhat better than those from FRAM v2.2 with the constrained sourcedetector distance. This method does not completely eliminate the source-detector distance dependency but can reduce it significantly. The calculation shows that it should be about a factor of 8 to 12 less dependent on the source-detector distance. The results in Fig. 8 prove it, even though, when compared with the results in Fig. 4, it is only a factor of about 7 less dependent. 


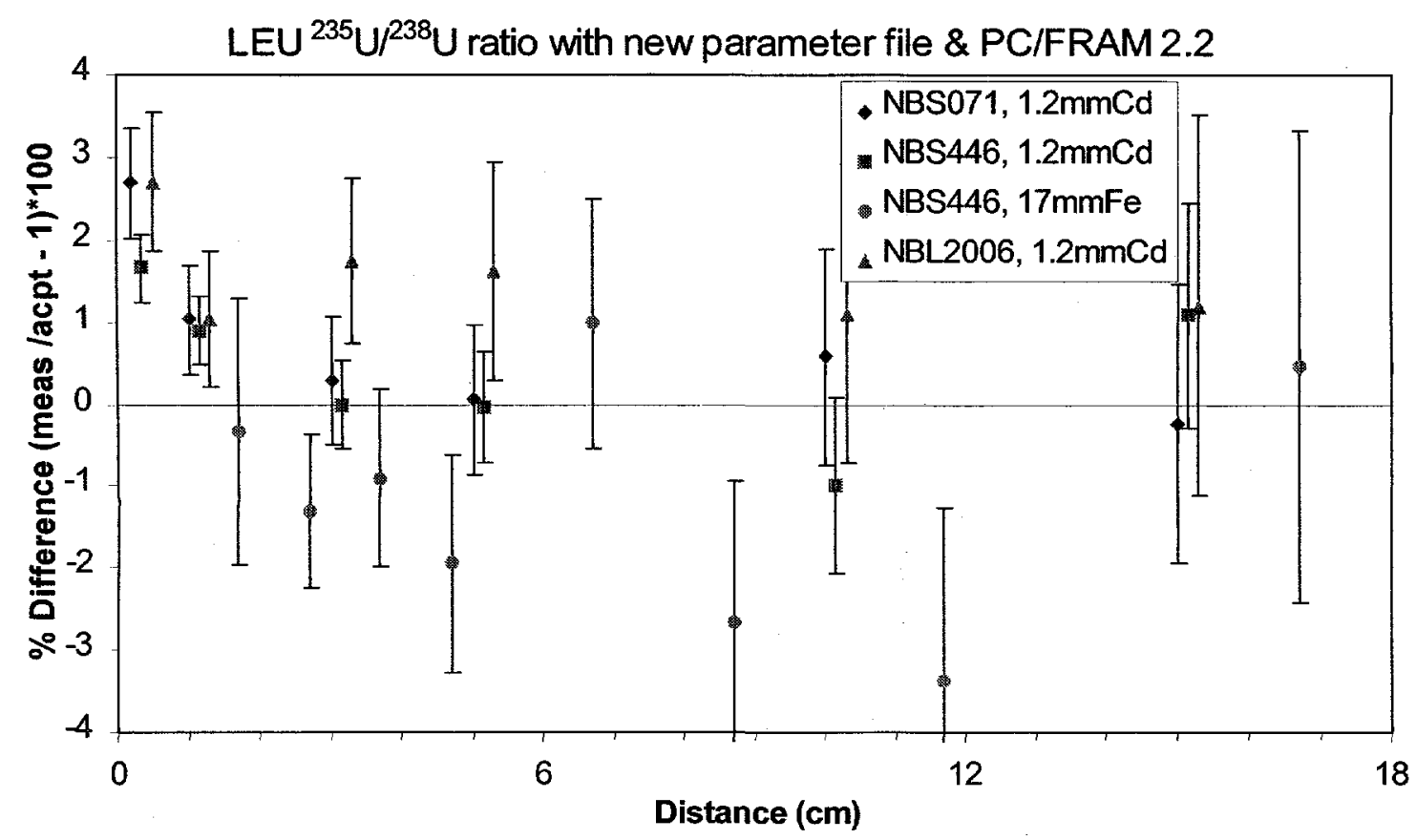

Fig. 8. Measurement bias as a function of source-detector distance.

4. Modified FRAM. Another method of correcting for the source-detector dependency is to correct the coincidence summing losses of the peaks. Attempts were made to correct the peak intensity using the current version of FRAM v2.2 by modifying the parameter file to include some negative-area peaks. The 766-, 786-, 880-, 883-, and 946-keV peaks were used to determine the coincidence summing correction factors for the other peaks of ${ }^{238} \mathrm{U}$. With the current version of FRAM, because these peaks are used for coincidence summing correction, they can not be used for relative efficiency. Therefore, only the 144-, 163-, 186-, and 205-keV peaks of ${ }^{235} \mathrm{U}$ and $258-, 569-, 743-$, and $1001-\mathrm{keV}$ peaks of the ${ }^{238} \mathrm{U}$ decay chain are used to determine the relative efficiency curve. This method works well with good data sets but not with weak data.

Why this method does not work with weak data is explained in the next few paragraphs. In FRAM, the 786-, 880-, 883-, and $946-\mathrm{keV}$ peaks were proportionally summed together and normalized to the 766-keV peak. The difference between the area of the normalized sum and that of the $766-\mathrm{keV}$ peak would be proportional to the average fractional coincidence summing losses of the 786-, 880-, 883-, and 946-keV peaks. That difference can be used to correct for the coincidence summing losses of all the peaks in the spectrum.

With FRAM, the normalized sum area is subtracted from the area underneath the $766-\mathrm{keV}$ peak. A least-squares fit is done on the subtracted region to find the area of the difference. This way of calculating the area differences, in theory, should give the same result as if the fitted 766-keV peak is subtracted from the sum area. However, in practice, it is not so. Normally, the peaks have small high-energy tails that are insignificant and can be ignored in the fitting of the peaks. However, when the area underneath the $766-\mathrm{keV}$ peak is subtracted from the sum area, the negligible high-energy tail becomes significantly large compared with the subtracted area. This large tail would add some extra counts to the subtracted area. This in effect overestimates the correction factor, which would in turn reduce the ${ }^{235} \mathrm{U} /{ }^{238} \mathrm{U}$ ratio by a small 
fraction. This factor alone accounts for the $1.5 \%$ differences of the calculated to expected ${ }^{235} \mathrm{U}{ }^{238} \mathrm{U}$ ratios. This effect is independent of the source-detector distance and adjusting the 258-keV peak BR upward by $1.5 \%$ can compensate it for.

However, the practice of subtracting the sum area from the peak area before fitting introduces a different type of error, which affects the weak spectra significantly. For a weak spectrum, especially the one taken with the source far away from the detector where the coincidence summing loss is about zero, the total counts of the subtracted area should be about zero with some channels having positive counts and some having negative counts. However, in the least-squares fit, FRAM sets the negative counts equal to zero. This would give the fit a positive peak area, which may be much larger than it should be. This result would overestimate the coincidence summing correction factor and thus reduce the ${ }^{235} \mathrm{U}^{238} \mathrm{U}$ ratio by as much as $5 \%$ or more. The effect depends on the peak areas and on source-detector distance: the farther the source-detector distance, the greater the effect.

The two reasons above explain why this method of correcting for the coincidence summing losses of the peaks using the current version of FRAM works only with good data but not with weak data. So it will not be considered.

The method of correcting for the coincidence summing losses of the peaks mentioned above would work if the FRAM code were modified to find the areas of the peaks first before subtracting them from the normalized peaks. There are two ways to do this. One is to change the code to work with a new parameter file where a flag is included to tell the code to subtract a peak from a dependent peak first before doing the least-squares fit to find the area. This method clearly has a big setback. If the code is modified to work with the modified parameter files, then it may not be able to work with the current, existing parameter files. So, the same as with the mentioned earlier method, it will not be considered further.

The second way is to embed the correction for the coincidence summing losses of the peaks inside the code. This method has one minor setback. If some better correction factors are found later, then it will not be easily incorporated into the working FRAM unless the code is modified again. The absolute coincidence summing losses of the gamma rays shown in Table I are likely to change if different detectors or sources are used. However, the relative coincidence summing losses should not vary much. The relative coincidence summing losses are used to determine the correction factors for gamma rays and not the absolute coincidence summing losses. Therefore, even in the event that better coincidence summing loss values are found later, the new correction factors would still not be able to improve much more than the code embedded with the current coincidence summing loss factors.

A beta version of the PC/FRAM v2.2 has been modified to include the coincidence summing correction factors to test the method. The modification only corrects the gamma rays of ${ }^{238} \mathrm{U}$ and ${ }^{228} \mathrm{Th}$ decay chains and does not affect the operations involving plutonium. Right after the peak areas are calculated and before the determination of the relative efficiency curve, the affected peaks are corrected for the coincidence summing losses. The 743-, 880-, 883-, and 946-keV peaks of the ${ }^{238} \mathrm{U}$ decay chain are used to calculate the coincidence summing correction factor. Those peaks are good ones to use because as we see in Table I, the 766- and $1001-\mathrm{keV}$ peaks of ${ }^{238} \mathrm{U}$ are several times more intense than any other gamma ray nearby, and they have no coincidence summing losses. Therefore, the correct relative efficiency curve would likely pass through or very near those two intense peaks. Comparisons of the relative efficiencies of the 743-, 880-, 883-, and 946-keV peaks with the relative efficiency curve would enable the determination of the relative correction factors for all the affected peaks in the spectrum. 
Note that Table I shows a fairly intense gamma ray at $786.3 \mathrm{keV}$. Using this peak in the calculation of the correction factor would add more statistics to the calculation and reduce the statistical error. It, however, was not used because of the interference of a weak but noticeable gamma ray of ${ }^{228} \mathrm{Th}$ at $785.5 \mathrm{keV}$. In most of the uranium sources, there exists some ${ }^{228} \mathrm{Th}$. If the $786.3-\mathrm{keV}$ peak is used in the calculation, then the interference of the $785.5-\mathrm{keV}$ peak of ${ }^{228} \mathrm{Th}$ must be taken into consideration.

After the FRAM code was modified, a parameter file for low-enriched uranium was constructed in the same way as the current parameter file. The BRs of the peaks used in the parameter file were from Table I. The 144-, 163-, 186-, and $205-\mathrm{keV}$ peaks of ${ }^{235} \mathrm{U}$ and the $258-, 742-, 766-, 880-, 883-, 946-$, and $1001-\mathrm{keV}$ peaks of ${ }^{238} \mathrm{U}$ were used to determine the relative efficiency curve. Note the $202-\mathrm{keV}$ peak of ${ }^{235} \mathrm{U}$ has some coincidence summing loss and since it is much less intense than other gamma rays near it, it is not worth to correct for its intensity. So it was not used. As with the current low-enriched parameter set, only the 258-keV peak was used to determine the activity of ${ }^{238} \mathrm{U}$.

As it turned out, the ${ }^{235} \mathrm{U} /{ }^{238} \mathrm{U}$ ratios from the samples determined with the new code and parameter file were about $0.4 \%$ too low. To correct for that, the BR of the $258-\mathrm{keV}$ peak was adjusted upward by $0.4 \%$, from $7.30 \mathrm{e}-4$ to $7.33 \mathrm{e}-4$. With this adjustment, the results are much better. Note that this adjustment of the $258-\mathrm{keV}$ peak would not in any way invalidate the BR results shown in Table I since the value added to the peak BR is well within the reported uncertainty.

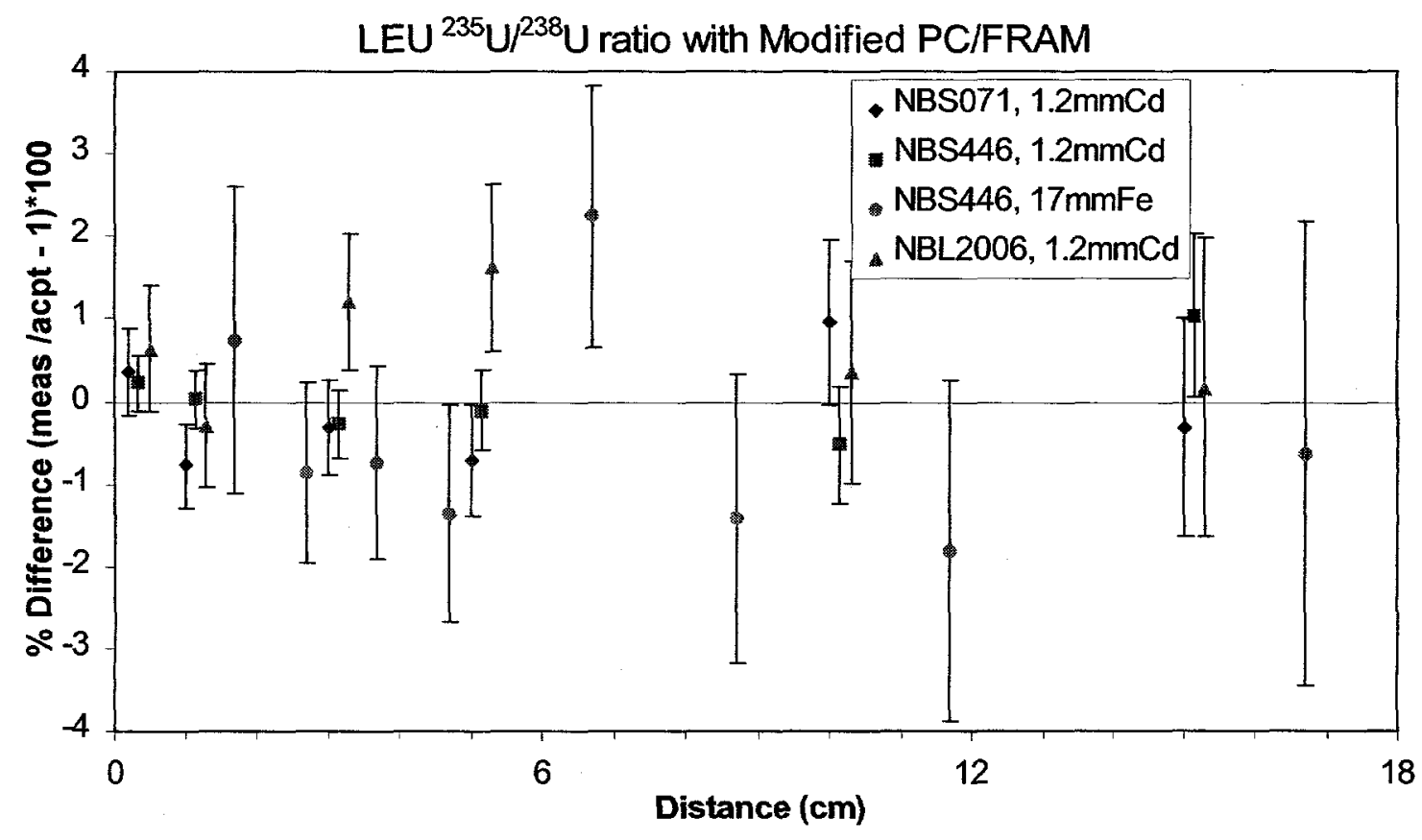

Fig. 9. Measurement bias as a function of source-detector distance.

Figure 9 shows the results of the analysis with the modified FRAM using the new parameter file for low-enriched uranium. We see that these results are much better than those from the unmodified FRAM and the source-detector distance dependency is completely eliminated. 


\section{B. High-Enriched Uranium Isotopic Determination}

Most high-enriched uranium contains a small amount of ${ }^{232} \mathrm{U}$. This in turn decays to ${ }^{228} \mathrm{Th}$ and then continues the decay chain to ${ }^{208} \mathrm{~Pb}$. In addition to the gamma rays of ${ }^{235} \mathrm{U}$ and ${ }^{238} \mathrm{U}$, the high-enriched parameter file also employs some of the gamma rays of ${ }^{232} U$ decay chain in its relative efficiency curve fitting. The gamma rays of ${ }^{232} \mathrm{U}$ decay chain used in the parameter file are also the same as the ${ }^{228}$ Th decay chain. The parameter file presents those gamma rays as from ${ }^{228}$ Th which is better since the calculated value from the FRAM code would truly represent the amount of ${ }^{228} \mathrm{Th}$ in the material but not of ${ }^{232} \mathrm{U}$ unless the material is more than 10 years old since the enrichment.

1. FRAM v2.2 with current parameter file. The current parameter file uses the 144-, 163-, 186-, 195-, and $205-\mathrm{keV}$ peaks of ${ }^{235} \mathrm{U}$, the $258-, 743-, 766-, 946-$, and $1001-\mathrm{keV}$ peaks of ${ }^{238} \mathrm{U}$, and the 238-, 583-, 727-, and $860-\mathrm{keV}$ peaks of ${ }^{232} \mathrm{U}_{-}{ }^{228} \mathrm{Th}$ decay chain to fit the relative efficiency curve. The BRs of ${ }^{235} \mathrm{U}$ are from Ref. 6 and the BRs of ${ }^{238} \mathrm{U}$ are from Ref. 7 (the same as in the current low-enriched uranium parameter file). The BRs of ${ }^{228} \mathrm{Th}$ are taken from Ref. 5. Figure 10 shows a typical relative efficiency curve fit of a high-enriched ${ }^{235} \mathrm{U}$ sample.

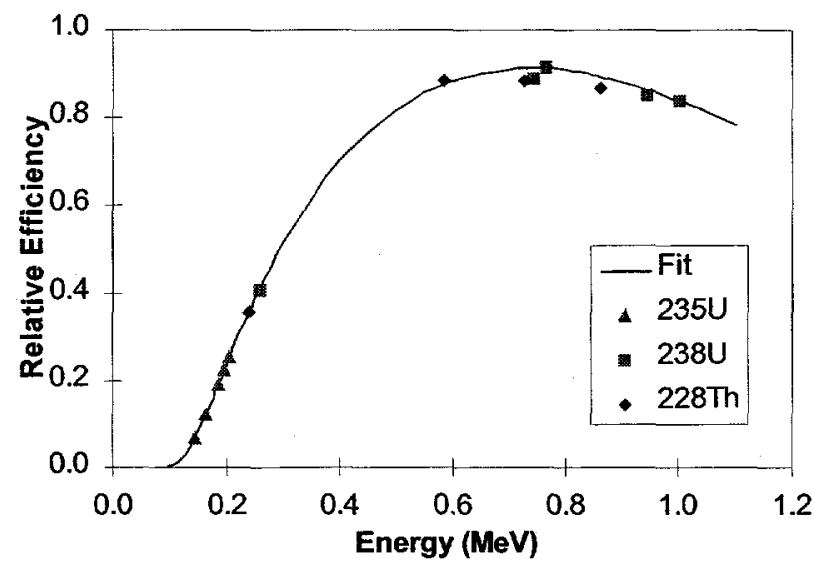

Fig. 10. Example of a relative efficiency curve of high-enriched uranium $\left(66.0 \%{ }^{235} U\right)$.

In high-enriched uranium, the intensity of the $258-\mathrm{keV}$ peak is much weaker and its role in the uranium isotopic analysis is much less important than in low-enriched uranium. For uranium enrichments greater than $90 \%$, the $258 \mathrm{-keV}$ peak is not even visible in the spectrum (Fig. 2). The $238-\mathrm{keV}$ peak of ${ }^{228} \mathrm{Th}$ now replaces the $258 \mathrm{-keV}$ peak in determining the normalization factors of the relative efficiency curve. The $238-\mathrm{keV}$ peak is the main one in the normalization of ${ }^{228} \mathrm{Th}$ to match ${ }^{235} \mathrm{U}$ in the efficiency fitting. The high-energy peaks of ${ }^{238} \mathrm{U}$, in turn, are normalized to the high-energy peaks of ${ }^{228} \mathrm{Th}$.

As seen in Table I, the 238-keV peak does not suffer the coincidence summing loss so the relative efficiency curve at energies below $300 \mathrm{keV}$ should be about right. However, the highenergy peaks of ${ }^{228} \mathrm{Th}$ suffer large coincidence summing losses, which tends to lower the curve at the high-energy end. This too low efficiency curve would affect the normalization of ${ }^{238} U$, making it appear to be more abundant than it should. This in turn would lower the ${ }^{235} \mathrm{U} /{ }^{238} \mathrm{U}$ ratio. So the source-detector dependency is that as the source is moved closer to the detector then 
the ${ }^{235} \mathrm{U} /{ }^{238} \mathrm{U}$ ratio would become smaller and the ratio is about right when the source is very far from the detector.

Note that even though the role of the $258-\mathrm{keV}$ peak of ${ }^{238} \mathrm{U}$ is not as important in highenriched uranium as in low-enriched uranium, it still contributes some to the normalization of the relative efficiency curve. Its coincidence summing effect tends to increase the ${ }^{235} \mathrm{U} /{ }^{238} \mathrm{U}$ ratio thus canceling the coincidence summing effect of the ${ }^{228} \mathrm{Th}$ peaks somewhat. As the enrichment increases, the significance of the $258-\mathrm{keV}$ peak becomes less (Fig. 2). For very highly enriched uranium (greater than $90 \%$ ), its peak intensity may almost completely disappear and should be removed from the relative efficiency curve's calculations. However, in this current high-enriched uranium parameter file it is left in for the whole range of enrichment because for very highly enriched sample, its peak's uncertainty is very large and it would not contribute to the overall isotopic results.

Figure 11 shows the results of the analysis with FRAM v2.2 using the current parameter file for high-enriched uranium. The data acquisition time for the NBL2006 with $1.2 \mathrm{~mm}$ of cadmium data was $8 \mathrm{~h}$ each. For the NBL5256 and NBL9318 with $2.0 \mathrm{~mm}$ of cadmium data, the acquisition time was $4 \mathrm{~h}$ each.

We see from Fig. 11 that the overall ${ }^{235} \mathrm{U} /{ }^{238} \mathrm{U}$ bias is a function of source-detector distance. So, for the FRAM code to work well with high-enriched uranium, one needs to remove the source-detector dependency.

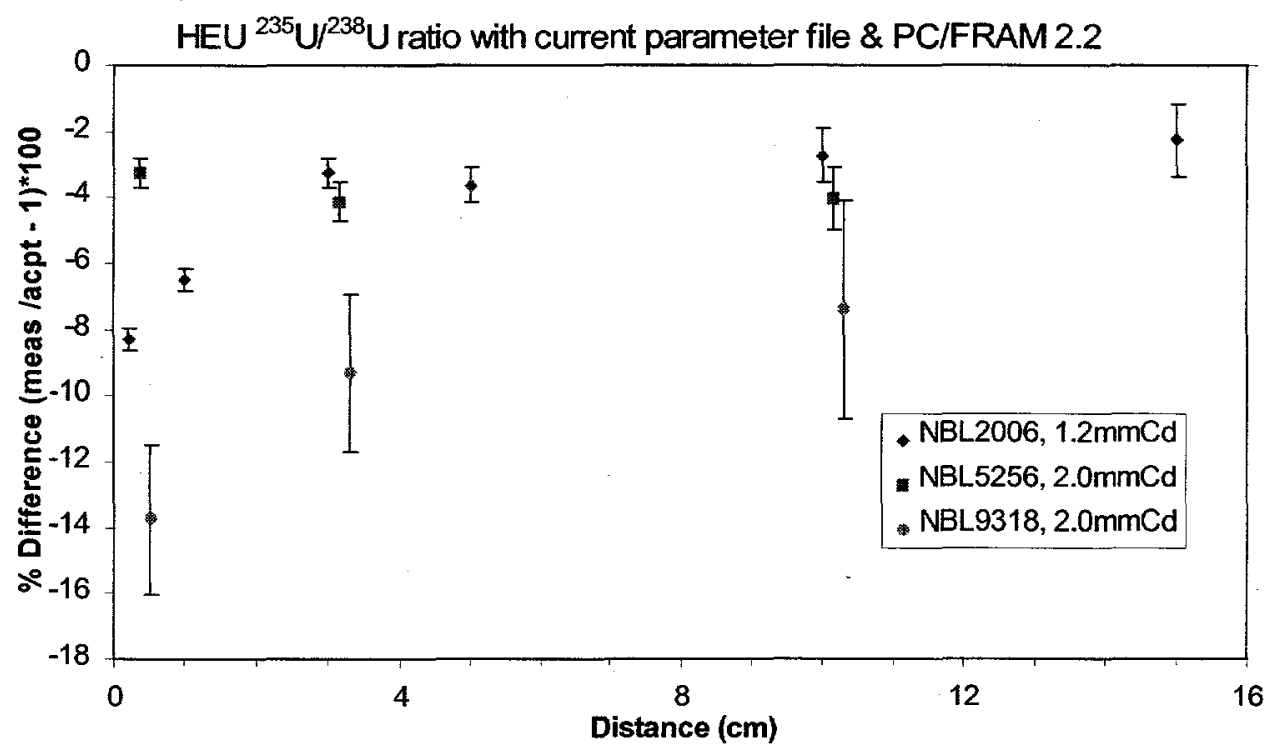

Fig. 11. Measurement bias as a function of source-detector distance. 


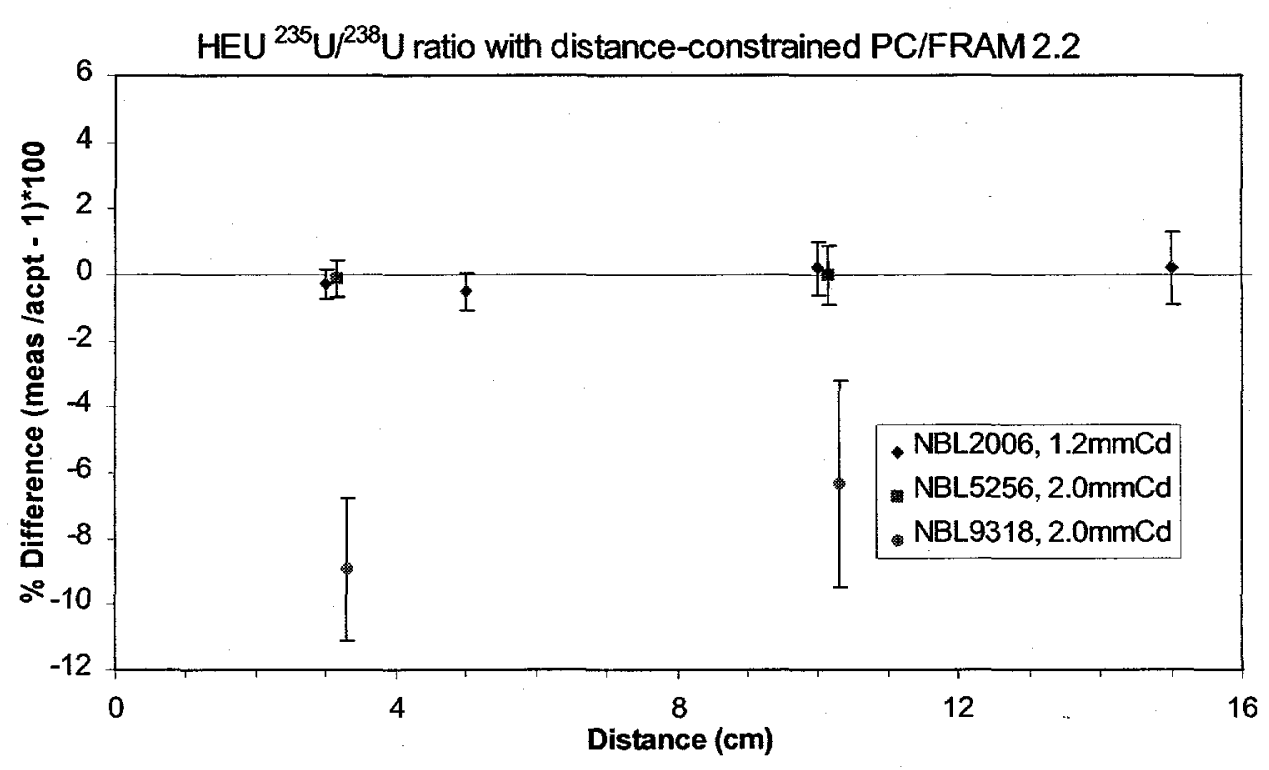

Fig. 12. Measurement bias as a function of source-detector distance.

2. FRAM v2.2 with constrained source-detector distance. Similar to the low-enriched uranium, the simplest method of reducing the source-detector distance dependency is to constrain the source-detector distance to greater than some distance, which in this case is $3 \mathrm{~cm}$. The BR of the $238-\mathrm{keV}$ peak of ${ }^{228} \mathrm{Th}$ is then adjusted (from $4.35 \mathrm{e}-1$ to $4.5 \mathrm{e}-1$ ) to shift the ${ }^{235} \mathrm{U} /{ }^{238} \mathrm{U}$ ratios upward to agree with the accepted results. Figure 12 shows the results.

We see that the $20 \%$ and $53 \%$ enriched results are good, but the $93 \%$ enriched results are not. Due to the complication of the peaks and the isotopes dependent on one another in the relative efficiency curve fit, it is not expected that a simple change of the $238-\mathrm{keV}$ peak's BR would be able to correct the biases of the whole high-enriched uranium range. To truly correct for the source-detector distance dependency for the whole range of high-enriched uranium, one needs to experiment with adjusting the BRs of many other peaks in the parameter file to find the correct combination.

One way of correcting for the very highly enriched uranium (such as the $93 \%$ enriched uranium above) is to create a separate parameter file for the very highly enriched uranium. The disadvantage will be one more parameter set in the database.

As with the low-enriched uranium, the big setback of this method is clearly the constrained source-detector distance.

3. FRAM v2.2 with new parameter file. Another method of removing the sourcedetector dependency for high-enriched uranium can also be used with the current FRAM v2.2.

Figure 13 shows the relative efficiency curves of high-enriched uranium fitted through both the hypothetical perfect and actual data points. Only the data points of ${ }^{235} \mathrm{U}$ and ${ }^{228} \mathrm{Th}$ are shown. The ${ }^{238} U$ data would normally be normalized to the high-energy end of the curve. The actual relative efficiency curve at high energy is somewhat lower than the perfect curve. This would increase the normalization factor for ${ }^{238} \mathrm{U}$. If either or both the 766- and 1001-keV peaks of ${ }^{238} \mathrm{U}$ are used to calculate the activity of ${ }^{238} \mathrm{U}$, then the ${ }^{238} \mathrm{U}$ fraction would be too large since those two gamma rays do not have any coincidence summing losses. If the 743-, 880-, 883-, and/or $946-\mathrm{keV}$ peaks of ${ }^{238} \mathrm{U}$ are used, the coincidence summing losses of these gamma rays will offset the differences between the perfect and actual relative efficiency curve somewhat and 
the results may come close to the expected values. How good the results are depend on many factors such as the fitting of the relative efficiency curve in the high-energy range, which peaks to use for the efficiency or activity, etc.

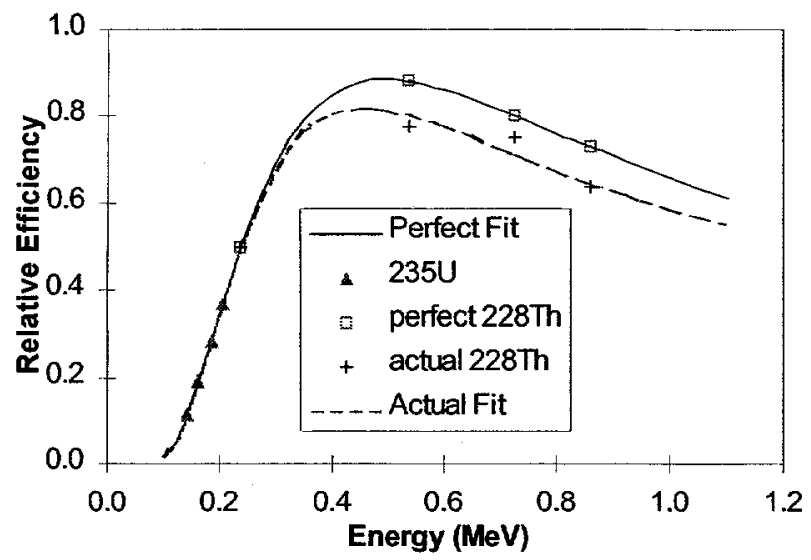

Fig. 13. Example of the relative efficiency curves of high-enriched uranium $\left(20 \%{ }^{235} U\right)$. The curves are fitted using the perfect and actual ${ }^{228}$ Th data points.

Experimenting with various combinations of the ${ }^{228} \mathrm{Th}$ and ${ }^{238} \mathrm{U}$ peaks found the best combination. It uses the 238-, 583-, 727-keV peaks of ${ }^{228} \mathrm{Th}$ and the $743-$ and $766-\mathrm{keV}$ peaks of ${ }^{238} \mathrm{U}$ for the efficiency and only the $743-\mathrm{keV}$ peak for the activity of ${ }^{238} \mathrm{U}$. For the very highly enriched uranium, where the $743-\mathrm{keV}$ peak may not be visible, the $766-\mathrm{keV}$ peak may be used for both the efficiency and activity of ${ }^{238} \mathrm{U}$. The BRs are from Table I.

Examining the coincidence summing losses of the peaks shown in Table I, we see that the coincidence summing losses of the $727-\mathrm{keV}$ peak of ${ }^{228} \mathrm{Th}$ and of the $743-\mathrm{keV}$ peak of ${ }^{238} \mathrm{U}$ are small and about the same. So if the $727-\mathrm{keV}$ peak (but not the $860-\mathrm{keV}$ peak of ${ }^{228} \mathrm{Th}$ ) is used for the relative efficiency fit, then the curve would pass close to the $727-\mathrm{keV}$ peak. This efficiency curve around $727 \mathrm{keV}$ would be lower than the perfect curve by a relative value of 0.04 . (This is a relative value. The absolute value would depend on the source-detector distance.) The $743-\mathrm{keV}$ peak has about the same relative coincidence summing loss, about 0.04 . So if this peak is used for the activity of ${ }^{238} \mathrm{U}$, it would offset the too low efficiency curve and the result will be close to the accepted value.

Figure 14 shows the results of the analysis with FRAM v2.2 using the new parameter file for high-enriched uranium. These results appear to be much better than those of FRAM v2.2 with the current parameter file, comparable to the distance-constrained FRAM v2.2, and the sourcedetector distance dependency seems to be eliminated. 


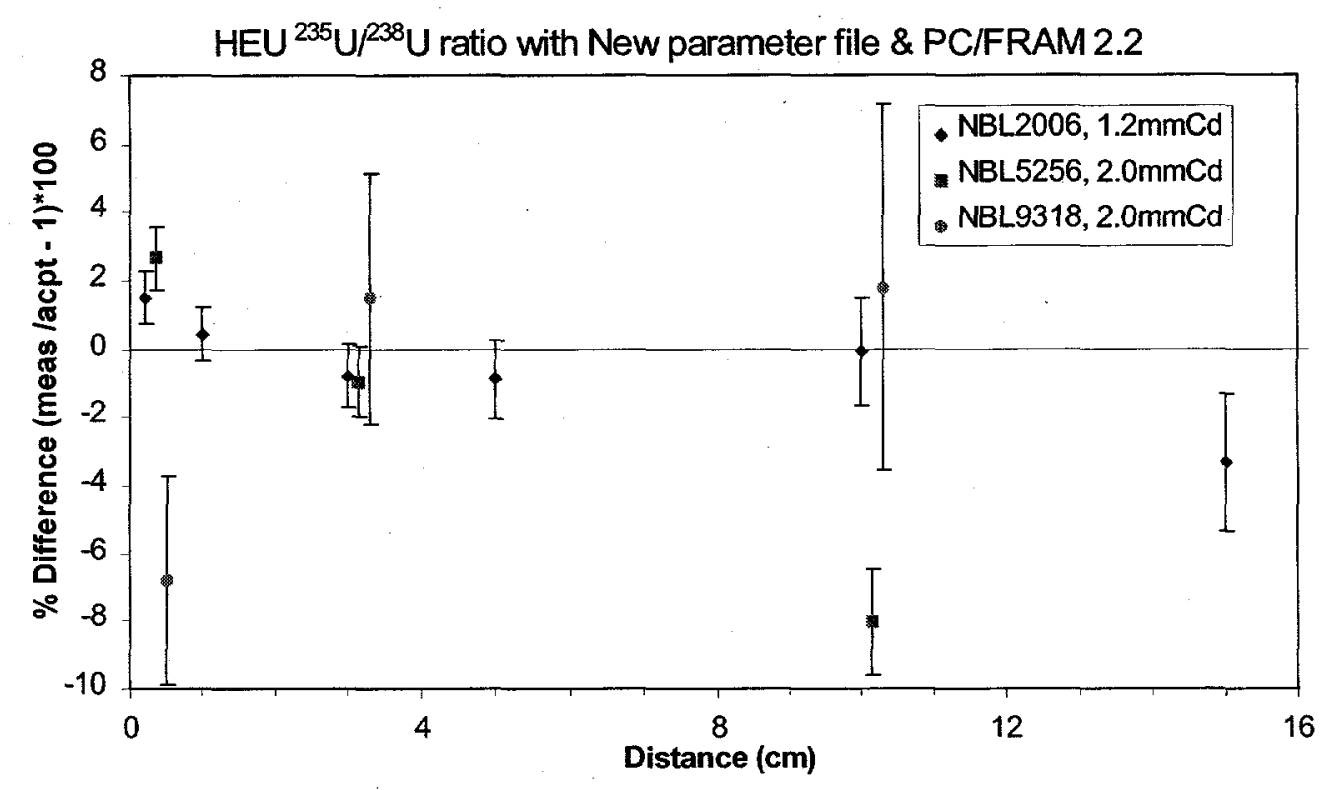

Fig. 14. Measurement bias as a function of source-detector distance.

4. Modified FRAM. A new high-enriched uranium parameter file was created to use with the modified FRAM code (which has already included the coincidence summing correction as was discussed earlier). The results are shown in Fig. 15. This parameter file used the 144-, 163-, 186-, and 205-keV peaks of ${ }^{235} \mathrm{U}$, the 258-, 743-, 766-, 880-, 883-, 946-, and 1001$\mathrm{keV}$ peaks of ${ }^{238} \mathrm{U}$, and the 238-, 583-, 727-, and $861-\mathrm{keV}$ peaks of the ${ }^{232} \mathrm{U}_{-}^{228} \mathrm{Th}$ decay chain to fit the relative efficiency curve. Only the $743-\mathrm{keV}$ peak is used to calculate the activity of ${ }^{238} \mathrm{U}$. The reason for using only the $743-\mathrm{keV}$ peak for the activity of ${ }^{238} \mathrm{U}$ will be discussed in the error analysis section.

We see that the results in Fig. 15 are much better than those in the Figs. 11, 12, and 14. Even though all three points of the $93 \%$ enrichment results do not quite agree with the uncertainties, they are still very close to expectation.

For very high-enriched uranium (greater than $90 \%$ ), the $258-\mathrm{keV}$ peak becomes so weak that it may be ignored in the fitting of the relative efficiency curve. Other peaks of ${ }^{238} \mathrm{U}(880$-, $883-$, and 946-keV peaks) may also be very weak and the coincidence summing correction based on these peaks may not be correct. In that case, the $202-\mathrm{keV}$ peak of ${ }^{235} \mathrm{U}$, the $727-$ and $861-\mathrm{keV}$ peaks of the ${ }^{232} U-{ }^{228}$ Th decay chain may also be used to calculate the coincidence summing correction factor. This is not implemented in this version of the modified FRAM. 


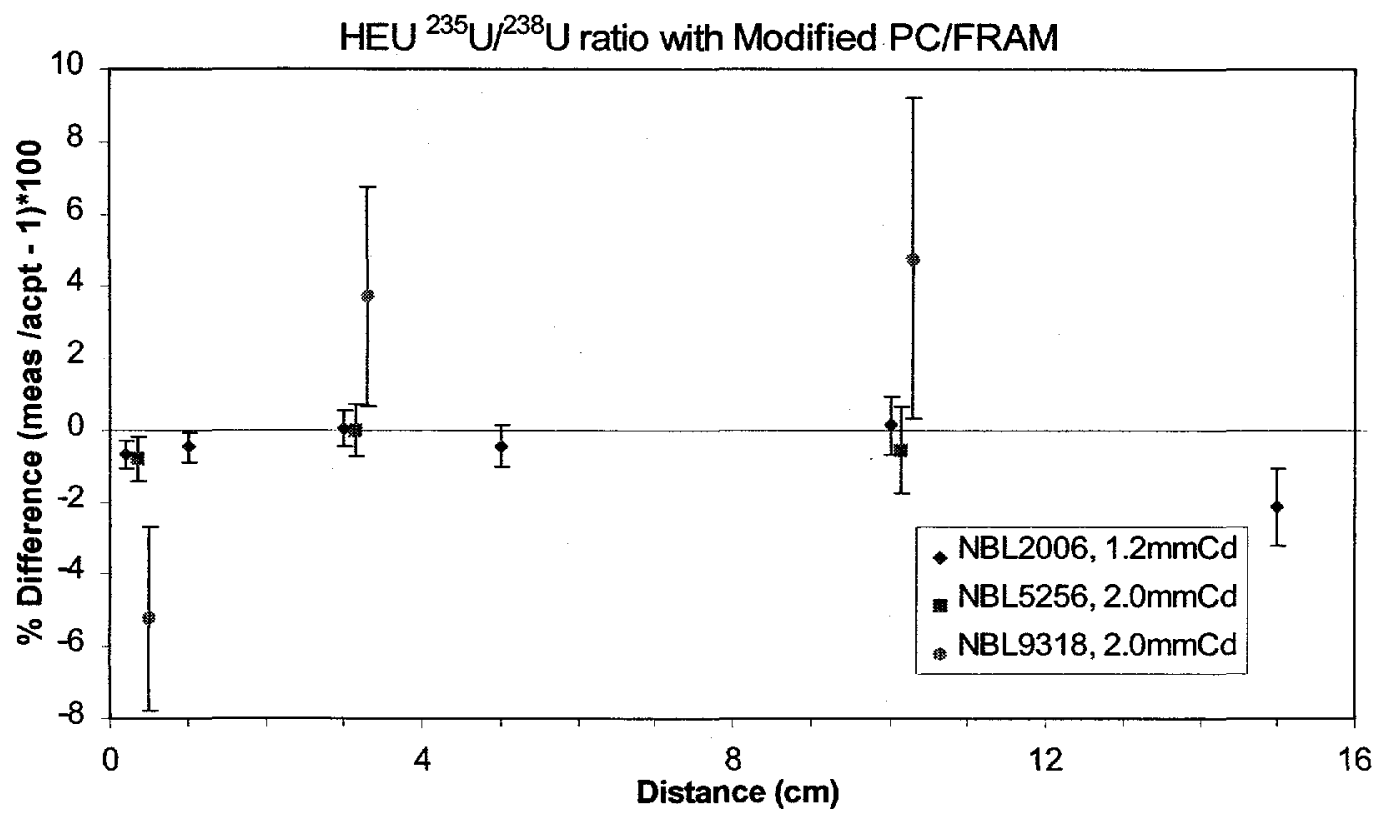

Fig. 15. Measurement bias as a function of source-detector distance.

\section{RESULTS WITH THE ARCHIVED DATA}

The results from all the methods have been shown for the NBS071, NBS446, NBL2006, NBL5256, and NBL9318 with various absorbers at various distances and various data-acquiring time. To further prove these methods, they are also tested with the archived data, which has the ${ }^{235} \mathrm{U}$ enrichment ranging from $0.3 \%$ up to $91.3 \%$. These data were taken for 1 -h count times, and each set of data for each source consists of many files, from 8 to 20 . The source-detector distances for these files are not known.

\section{A. Low-Enriched Uranium}

Figure 16 displays the results of low-enriched uranium (ranging from $0.3 \%$ to $66.0 \%$ ). The values for the FRAM with new parameter file and the modified FRAM are shifted slightly to the right for clarity. Each error bar represents the standard deviation of a data set with multiple runs, 1-h data acquisition for each. The low-enriched uranium is extended up to $66 \%{ }^{235} \mathrm{U}$ enrichment to show that these methods would work with moderately high-enriched uranium and may be used when only natural uranium is used in the enrichment process (thus no ${ }^{228} \mathrm{Th}$ is present for the high-enriched uranium parameter files).

We see that the errors for the three methods are about the same. The results of the FRAM v2.2 with the new parameter file and of the modified FRAM agree well with the accepted values (well within the uncertainties). However, for the FRAM v2.2 with the current parameter file, the results are poor for enrichments above $10 \%$. For enrichments below $10 \%$, the results seem to agree, but that may be misleading. It is because these data files were used to construct the current parameter file and so their results should agree with the accepted value. If the data were reacquired at some arbitrary distance, then the results would likely not agree with the accepted one (as they are with the data shown earlier at various source-detector distances). 


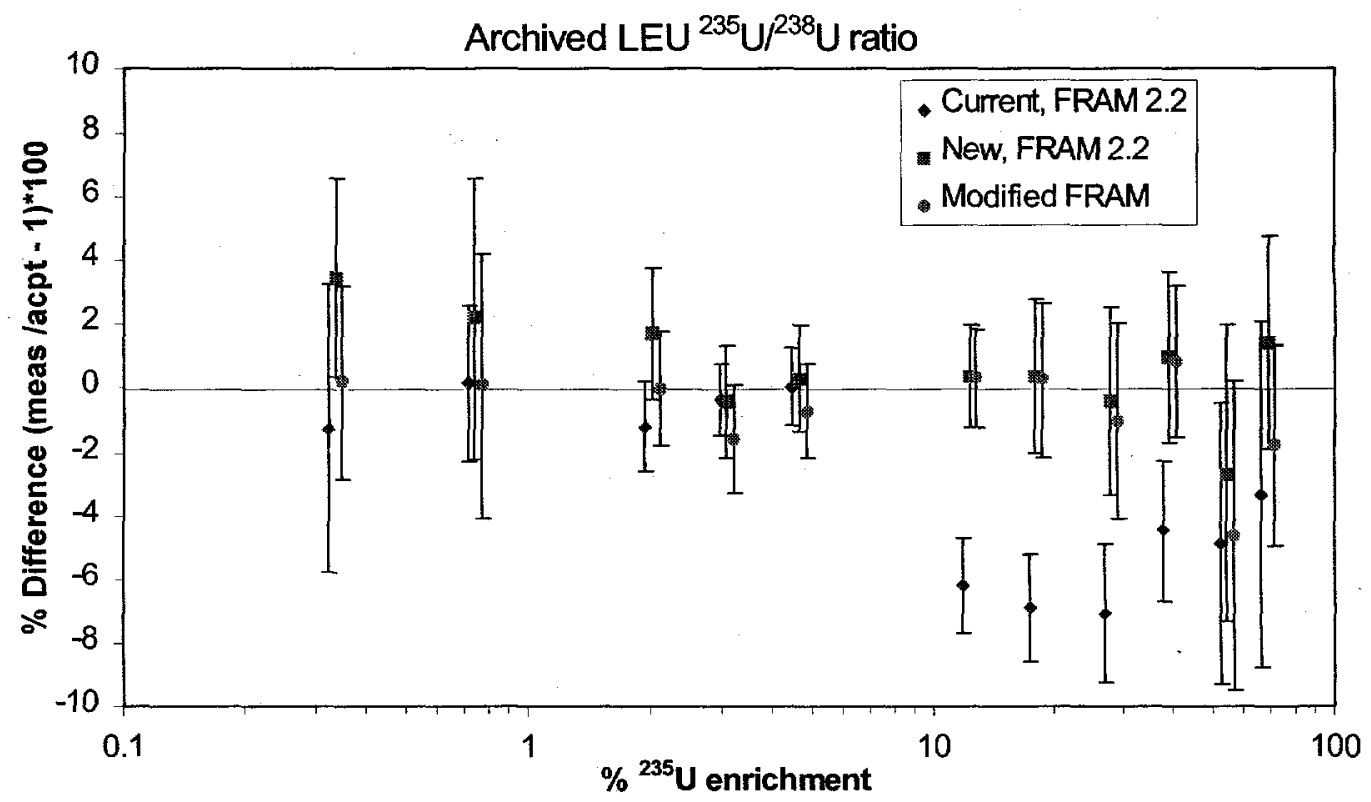

Fig. 16. Results of the three methods with low-enriched uranium. The distance-constrained FRAM method is not shown.

Due to the unknown source-detector distances of the archived data, the distanceconstrained FRAM method was not used. Also, based on the results of FRAM v2.2 with the current parameter file, it can be deduced that these files were taken with the source-detector distances smaller than the 5-cm limit of the distance-constrained FRAM method. Thus, if the results with the distance-constrained FRAM method were shown, they would not fare well compared with other methods.

\section{B. High-Enriched Uranium}

Figure 17 displays the results using high-enriched uranium parameter files for samples from $11.8 \%$ to $91.3 \%{ }^{235} \mathrm{U}$. The results with the distance-constrained FRAM method are not shown. The values for FRAM v2.2 with new parameter file and the modified FRAM are shifted slightly to the right for clarity. Each error bar represents the standard deviation of a data set with multiple runs, 1 -h data acquisition each.

The errors for the FRAM v2.2 with the current parameter file and the modified FRAM are about the same, while those for the FRAM v2.2 with the new parameter file are slightly larger. As for the biases, the FRAM v2.2 with the new parameter file and the modified FRAM appear to have no bias overall, while the results of the FRAM v2.2 with the current parameter file do not agree with the accepted values. 


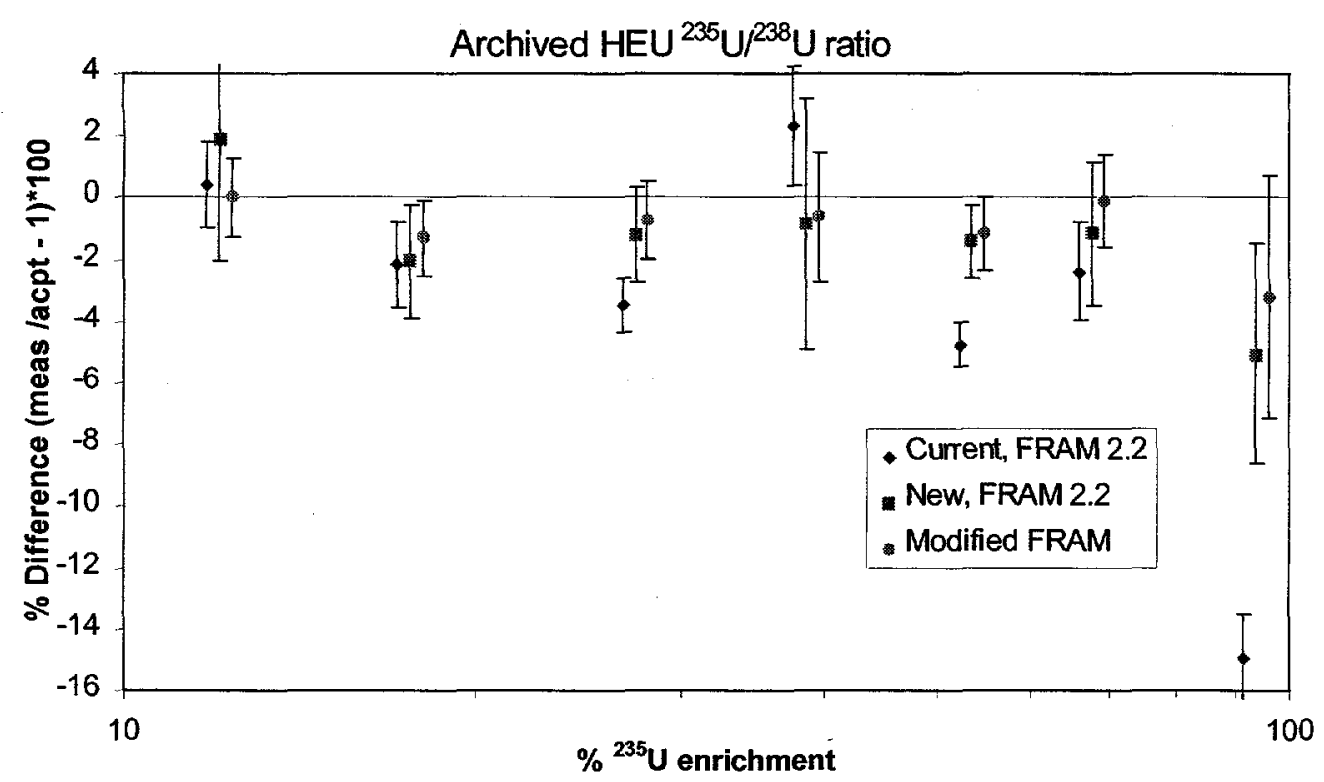

Fig. 17. Results of the three methods with high-enriched uranium. The distance-constrained FRAM method is not shown. The horizontal axis is in log scale.

\section{ERROR ANALYSIS}

\section{A. Determination Of The True Statistical Error}

The current version of FRAM v2.2 ignores the uncertainty of the relative efficiency curve fitting in its error propagation. Therefore, the errors reported by the FRAM code do not generally represent the true errors of the data. The true error would equal the reported error multiplied by some factor $F$ (normally greater than one). The true errors for all the methods were found using the archived data with the enrichment from $0.3 \%$ up to $91.3 \%$. For each set of data with each method, the standard deviation of multiple runs is taken to represent the true statistical error of the method at that certain enrichment. The true error is then divided by the reported error to find the factor $F$. After the factor $F \mathrm{~s}$ of various enrichment data are found, they are fitted to the equation $[F=\operatorname{aexp}(\mathrm{b} / X)]$, where $X$ represents the percentage enrichment of ${ }^{235} \mathrm{U}$ and $\mathrm{a}$ and $\mathrm{b}$ are some constants. (Many other forms were also tried but this form was the best.) Table II shows the results. These factor $F \mathrm{~s}$ were used with the reported errors in calculating the true statistical errors of the results shown in Figs. 4, 5, 8, 9, 11, 12, 14, and 15.

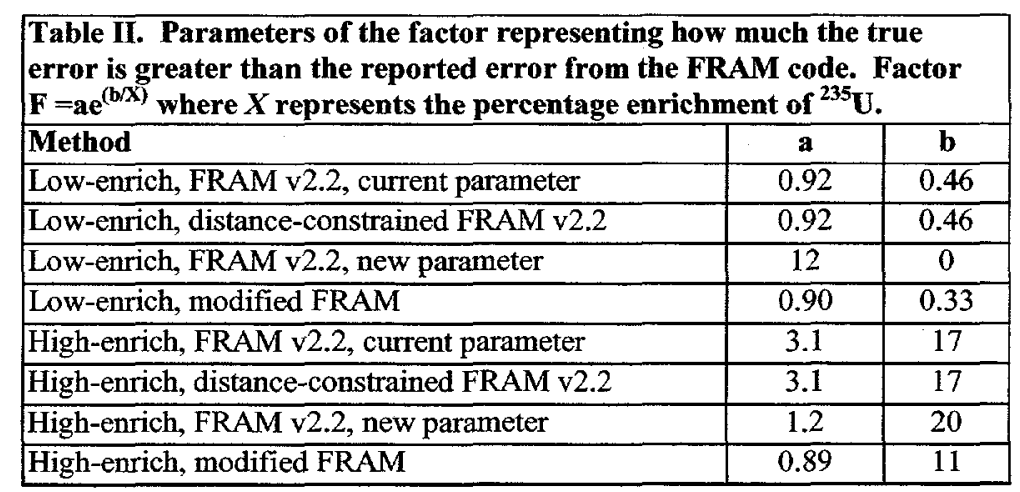


In the future, when FRAM includes the uncertainty of the relative efficiency curve fitting in its error propagation, the reported errors might better correspond to the true statistical errors.

\section{B. Low-Enriched Uranium}

For the FRAM v2.2 with the current parameter file, the error of the ${ }^{235} \mathrm{U}$ or ${ }^{238} \mathrm{U}$ fraction comes mostly from the statistical error of the $258-\mathrm{keV}$ peak of ${ }^{238} \mathrm{U}$ and some from the fitting of the peaks of ${ }^{235} \mathrm{U}$. As the enrichment increases, the intensities of the ${ }^{235} \mathrm{U}$ peaks increase and the errors of the uranium fractions approach that of the statistical error of the $258-\mathrm{keV}$ peak. The reported error from FRAM with this parameter file is entirely from the $258-\mathrm{keV}$ peak. The true error should be about 2 times the reported error for natural uranium and is reduced to about 1 time the reported error for the enrichment of about $2 \%$ or higher.

The distance-constrained FRAM uses the same parameter file (with a slightly modified BR of the $258-\mathrm{keV}$ peak) as the current parameter file, so its true errors are the same as those of the FRAM v2.2 with the current parameter file.

For the FRAM v2.2 with the new parameter file, the error of the uranium fractions is the same as that of FRAM v2.2 with the current parameter file plus the uncertainty of fitting the high-energy peaks of ${ }^{238} U$. This method, has somewhat larger statistical errors, but it has no source-detector distance biases. This method uses only the $1001-\mathrm{keV}$ peak to determine the activity of ${ }^{238} \mathrm{U}$, and the reported error from the FRAM code comes entirely from the statistical uncertainty of this peak, which is too small. The true error is about 12 times greater than the reported error.

For the modified FRAM, the errors of the uranium fractions are the same as FRAM v2.2 with the current parameter file plus the uncertainty of correcting for the attenuated peaks of ${ }^{238} \mathrm{U}$. It turns out that the error due to peak intensity correction is small and the overall error is about the same as that of the FRAM with the current parameter file.

\section{High-Enriched Uranium}

For the FRAM v2.2 with the current parameter file, the errors of the uranium fractions come mostly from the normalization of the peaks of ${ }^{228} \mathrm{Th}$ and ${ }^{238} \mathrm{U}$. As the enrichment increases, the intensities of the ${ }^{228}$ Th peaks increase and the errors of the uranium fractions approach that of the fitting and normalizing of the ${ }^{238} \mathrm{U}$ peaks. The current parameter set uses many peaks in the calculations of the activity of ${ }^{238} \mathrm{U}$. The reported error from FRAM with this parameter set is from the statistical errors of those peaks and is about 10 to 3 times smaller than the true error for the enrichment ranging from $12 \%$ to $93 \%$.

The same error analysis can also be applied to the distance-constrained FRAM since they both use almost the same parameter files.

For the FRAM v2.2 with the new parameter file, the errors of the uranium fractions come mostly from the statistical error of the $743-\mathrm{keV}$ peak of ${ }^{238} \mathrm{U}$ and from the fitting of the peaks of ${ }^{228} \mathrm{Th}$. As the enrichment increases, the true statistical error comes close to the reported error, which is entirely from the statistical uncertainty of the $743-\mathrm{keV}$ peak. It is about 6 to 1.5 times smaller than the true error for the enrichment ranging from $12 \%$ to $93 \%$.

For the modified FRAM, the errors of the uranium fractions come mostly from the fitting of the peaks of ${ }^{228} \mathrm{Th}$, the peaks used in the ${ }^{238} \mathrm{U}$ activity determination, plus the uncertainties of correcting for the attenuated peaks of ${ }^{228} \mathrm{Th}$ and ${ }^{238} \mathrm{U}$. For this parameter set, only the $743-\mathrm{keV}$ is used to determine the ${ }^{238} \mathrm{U}$ activity. The true statistical error is about 2 to 1 times smaller than the true error for the enrichment ranging from $12 \%$ to $93 \%$. The reason for using only the $743-\mathrm{keV}$ 
peak for the activity of ${ }^{238} \mathrm{U}$ and not the $766-\mathrm{keV}$ (which has more than three times the activity) or combination of these two and other peaks is that the main error comes from the correction of the intensity-attenuated peaks. As the enrichment increases, the fraction of ${ }^{228} \mathrm{Th}$ increases and reduces the error. However, the fraction of ${ }^{238} \mathrm{U}$ is decreased and it would reduce the statistic of the ${ }^{238} \mathrm{U}$ peaks. This reduced, ${ }^{238} \mathrm{U}$ would increase the peak coincidence summing correction error and it would also in turn increase the error of the fitting of the ${ }^{228} \mathrm{Th}$ peaks because these peaks are also affected. Using other peaks or more peaks of ${ }^{238} \mathrm{U}$ for the activity determination would not reduce the error and it would have a setback that the reported error would be too small.

In future versions of FRAM, when the uncertainty of the relative efficiency curve fitting is included in the error propagation, one will use either the $766-\mathrm{keV}$ or the $1001-\mathrm{keV}$ peak or a combination of any peaks to determine the activity of ${ }^{238} \mathrm{U}$. The reported errors would then still be correct regardless of what peaks are used for the activity.

It is noted that for all these methods, the errors and the peaks used in the high-enriched uranium are almost independent from the errors and the peaks used in the low-enriched uranium. Therefore, for the ${ }^{235} \mathrm{U}$ enrichment in the range of $10 \%$ to $70 \%$, both the low- and high-enriched uranium parameter sets can be used and the final result can be the average of the two. This would increase the accuracy of the results.

Also note that for very high-enriched uranium (greater than $70 \%{ }^{235} \mathrm{U}$ ), the error in the ${ }^{235} \mathrm{U}$ fraction is much smaller than the error in the ${ }^{235} \mathrm{U} /{ }^{238} \mathrm{U}$ ratio. The result that most people want is the fraction of ${ }^{235} \mathrm{U}$, so it is not as bad as the ${ }^{235} \mathrm{U} /{ }^{238} \mathrm{U}$ ratio results reported in this paper.

\section{SUMMARY}

Each of the methods described has some advantages and disadvantages compared with one another. Depending on how much one cares for the accuracy of the results or how difficult to modify the parameter files or the code, one should choose one method over the others. Table III summarizes the advantages and disadvantages of these methods.

The current uranium parameter sets with FRAM v2.2 need to be replaced and the question is which method should be used: the distance-constrained FRAM v2.2, the FRAM v2.2 with the new parameter files, or the modified FRAM? The distance-constrained FRAM is the simplest and its performance is almost as good as the other two methods, but its biggest setback is the constrained source-detector distance. The performance of the FRAM v2.2 with the new parameter files is second best but it has one main setback: the reported error is too small. The performance of the modified FRAM appears to be the best (in both reported results and errors), but the code must be modified. This is believed to be the most difficult obstacle to overcome. 


\begin{tabular}{|c|c|c|}
\hline Method & Advantages & Disadvantages \\
\hline $\begin{array}{l}\text { Low-enriched, FRAM } \\
\text { v2.2, current parameter }\end{array}$ & $\begin{array}{l}\text { No need to change anything; reported } \\
\text { error is about the same as the true } \\
\text { statistical error. }\end{array}$ & $\begin{array}{l}\text { Source-detector distance bias is large, much } \\
\text { larger than the statistical error; results are not } \\
\text { reliable if source-detector distance is not } \\
\text { known. }\end{array}$ \\
\hline $\begin{array}{l}\text { Low-enriched, distance- } \\
\text { constrained FRAM v2.2 }\end{array}$ & $\begin{array}{l}\text { No need to change FRAM code; simple } \\
\text { change of parameter file; reported error is } \\
\text { about the same as the true statistical error; } \\
\text { small source-detector distance bias. }\end{array}$ & $\begin{array}{l}\text { Constrained source-detector distance; results } \\
\text { are not reliable if source-detector distance is } \\
\text { not known. }\end{array}$ \\
\hline $\begin{array}{l}\text { Low-enriched, FRAM } \\
\text { v2.2, new parameter }\end{array}$ & $\begin{array}{l}\text { No need to change FRAM code; negligible } \\
\text { source-detector distance dependency. }\end{array}$ & $\begin{array}{l}\text { Reported error is much smaller than true } \\
\text { statistical error. }\end{array}$ \\
\hline $\begin{array}{l}\text { Low-enriched, modified } \\
\text { FRAM }\end{array}$ & $\begin{array}{l}\text { Results are correct; no source-detector } \\
\text { distance dependency; reported error is } \\
\text { about the same as the true statistical error. }\end{array}$ & Need to modify FRAM code. \\
\hline $\begin{array}{l}\text { High-enriched, FRAM } \\
\text { v2.2, current parameter }\end{array}$ & No need to change anything. & $\begin{array}{l}\text { Source-detector distance bias is large, much } \\
\text { larger than the statistical error; results are not } \\
\text { reliable if source-detector distance is not } \\
\text { known; reported error is much smaller than } \\
\text { true statistical error. }\end{array}$ \\
\hline $\begin{array}{l}\text { High-enriched, distance- } \\
\text { constrained FRAM v } 2.2\end{array}$ & $\begin{array}{l}\text { No need to change FRAM code; simple } \\
\text { change of parameter file; small source- } \\
\text { detector distance bias. }\end{array}$ & $\begin{array}{l}\text { Constrained source-detector distance; results } \\
\text { are not reliable if source-detector distance is } \\
\text { not known; reported error is much smaller than } \\
\text { true statistical error. }\end{array}$ \\
\hline $\begin{array}{l}\text { High-enriched, FRAM } \\
\text { v2.2, new parameter }\end{array}$ & $\begin{array}{l}\text { No need to change FRAM code; negligible } \\
\text { source-detector distance dependency. }\end{array}$ & $\begin{array}{l}\text { Slightly larger errors than other methods; } \\
\text { reported error is somewhat smaller than true } \\
\text { statistical error. }\end{array}$ \\
\hline $\begin{array}{l}\text { High-enriched, modified } \\
\text { FRAM v2.2 }\end{array}$ & $\begin{array}{l}\text { Results are correct; no source-detector } \\
\text { distance dependency; reported error is } \\
\text { about the same as the true statistical error. }\end{array}$ & Need to modify FRAM code. \\
\hline
\end{tabular}

\section{REFERENCES}

1. T. E. Sampson, "Plutonium Isotopic Composition by Gamma-Ray Spectroscopy: A Review," Los Alamos National Laboratory report LA-10750-MS (1986).

2. T. E. Sampson, G. W. Nelson, and T. A. Kelley, "FRAM: A Versatile Code for Analyzing the Isotopic Composition of Plutonium from Gamma-Ray Pulse Height Spectra," Los Alamos National Laboratory report LA-11720-MS (1989).

3. T. A. Kelley, T. E. Sampson, and D. DeLapp, "PC/FRAM: Algorithms for the Gamma-Ray Spectrometry Measurement of Plutonium Isotopic Composition," Fifth International Conference on Facility Operations - Safeguard Interface, Jackson Hole, Wyoming, September 24-29, 1995, Los Alamos National Laboratory document LA-UR-95-3326.

4. D. T. Vo, T. E. Sampson, and P. Staples, "Corrections for the Emissions Probabilities of the Intense Gamma Rays from ${ }^{238} \mathrm{U}$ and Applying them to Uranium Isotopic Analysis," Nucl. Mater. Manage. (Proc. Issue) XXVII (1996). 
5. R. B. Firestone and V.S. Shirley, "Table of Isotopes," $8^{\text {th }}$ ed. (John Wiley \& Sons, Inc., New York, 1996).

6. M. F. Banham and R. Jones, "Gamma-Ray-Spectrometry Measurements for Actinide Decay-Scheme Studies with Particular Reference to ${ }^{231} \mathrm{~Pa}$ and ${ }^{235} \mathrm{U}$," Int. J. Appl. Radiat. Isot. 34:8 pp. 1225-1231 (1983).

7. H. L. Scott and K. W. Marlow, "Gamma-Ray Emission Probabilities of the Daughters of ${ }^{238} \mathrm{U}, "$ Nucl. Inst. \& Meth. in Phys. Res. A286 pp. 549-555 (1990). 